\title{
ASSESSMENT OF A STEADY-STATE PROPANE-GAS TRACER METHOD FOR DETERMINING REAERATION COEFFIENTS, CHENANGO RIVER, NEW YORK
}

by N. Yotsukura, D.A. Stedfast, and G.H. Jirka 


\section{UNITED STATES DEPARTMENT OF THE INTERIOR}

WILLLIAM P. CLARK, Secretary

\section{GEOLOGICAL SURVEY}

Dallas L. Peck, Director

For additional information write to:

Office of the Regional Research Hydrologist

U.S. Geological Survey, WRD

430 National Center

Reston, Virginia 22092
Copies of the report can be purchased from:

U.S. Geological Survey

Western Distribution Branch Open-File Services Section Box 25425, Federal Center Denver, Colorado 80225 
Abstract $\ldots \ldots \ldots \ldots \ldots \ldots \ldots \ldots \ldots \ldots \ldots \ldots \ldots \ldots \ldots \ldots \ldots \ldots \ldots \ldots \ldots \ldots \ldots \ldots$

Introduction $\ldots \ldots \ldots \ldots \ldots \ldots \ldots \ldots \ldots \ldots \ldots \ldots \ldots \ldots \ldots \ldots \ldots \ldots \ldots \ldots$

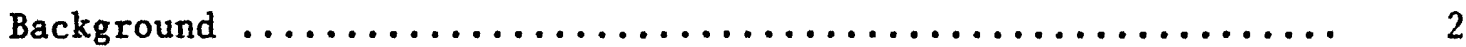

Purpose and scope $\ldots \ldots \ldots \ldots \ldots \ldots \ldots \ldots \ldots \ldots \ldots \ldots \ldots \ldots \ldots$

Acknowledgments ............................. 6

Equations for dissolved gas concentration $\ldots \ldots \ldots \ldots \ldots \ldots \ldots$

Description of field test $\ldots \ldots \ldots \ldots \ldots \ldots \ldots \ldots \ldots \ldots \ldots \ldots \ldots \ldots \ldots$

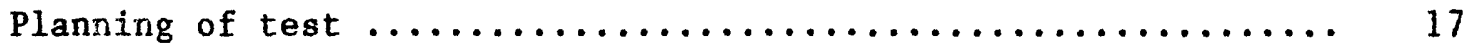

Preliminary dye test, Aug. 3, $1982 \ldots \ldots \ldots \ldots \ldots \ldots \ldots \ldots \ldots \ldots \ldots$

Main tracer test, Aug. $4-5,1982 \ldots \ldots \ldots \ldots \ldots \ldots \ldots \ldots \ldots \ldots \ldots \ldots$

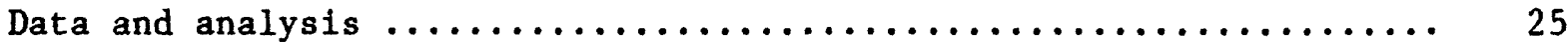

Mean travel time, $E$, and correction term, $E \ldots \ldots \ldots \ldots \ldots \ldots$

Mass distribution factor, $\phi \ldots \ldots \ldots \ldots \ldots \ldots \ldots \ldots \ldots \ldots \ldots \ldots \ldots \ldots$

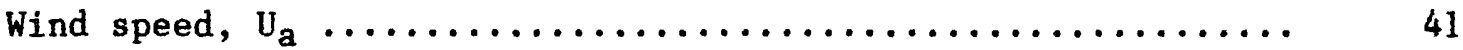

Propane desorption coefficient, $\mathrm{K}^{\mathrm{r}} \ldots \ldots \ldots \ldots \ldots \ldots \ldots \ldots \ldots \ldots$

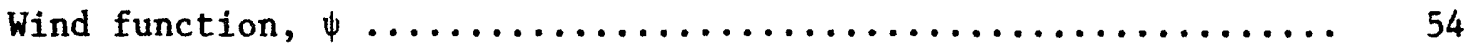

Discussion $\ldots \ldots \ldots \ldots \ldots \ldots \ldots \ldots \ldots \ldots \ldots \ldots \ldots \ldots \ldots \ldots \ldots \ldots \ldots \ldots \ldots$

Field procedures $\ldots \ldots \ldots \ldots \ldots \ldots \ldots \ldots \ldots \ldots \ldots \ldots \ldots \ldots \ldots \ldots \ldots$

Desorption coefficient, $\mathrm{K}^{\mathrm{r}} \ldots \ldots \ldots \ldots \ldots \ldots \ldots \ldots \ldots \ldots \ldots \ldots \ldots$

Wind function, $\psi \ldots \ldots \ldots \ldots \ldots \ldots \ldots \ldots \ldots \ldots \ldots \ldots \ldots \ldots \ldots \ldots$

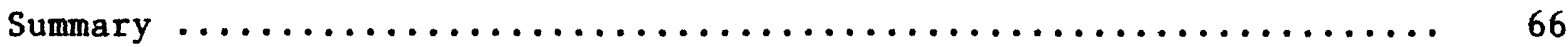

References $\ldots \ldots \ldots \ldots \ldots \ldots \ldots \ldots \ldots \ldots \ldots \ldots \ldots \ldots \ldots \ldots \ldots \ldots \ldots \ldots \ldots \ldots \ldots$ 


\section{ILLUSTRATIONS}

Figure 1. Sketch of the Chenango River study reach near Binghamton, New York-1

Figure 2. Sketch of the wind measurement station- 26

Figure 3. Temporal variation of dye concentration at the upstream cross section, August 5, 1982

Figure 4. Temporal variation of dye concentration at the downstream cross section, August 5, 1982

Figure 5. Temporal variation of dye concentration at the upstream cross section, August 4, 1982

Figure 6. Temporal variation of dye concentration at the downstream cross section, August 4, 1982

Figure 7. Transverse variation of the measured and simulated mass distribution factors

Figure 8. Temporal variations of gas concentration and wind speed at the upstream cross section, August 4-5, 1982---

Figure 9. Temporal variations of gas concentration and wind speed at the downstream cross section, August 4-5, 1982- -

Figure 10. Temporal variations of propane desorption coefficient, wind speed, and water temperature, August 4-5, 1982-----

Figure 11. A summary of film transfer coefficient of propane and reach-averaged flow parameters-

Figure 12. Relation between wind function and wind speed at the upstream cross section 
TABLES

Page

Table 1. Four moments of dye concentration distribution, August 5, $1982-0$

Table 2. Mass distribution factor at the upstream cross section calculated by equation 36, August 4, 1982-_-

Table 3. Temporal variations of wind speed, wind direction, air and water temperature, and relative humidity, August $4-5,1982-1$

Table 4. Steady-state period and mean travel time for propane at six measurement locations, August 4-5, 1982- 46

Table 5. Propane desorption coefficients along 10 percent streamline calculated by equation 22

Table 6. Propane desorption coefficients along 30 percent streamline calculated by equation 22

Table 7. Wind functions at the upstream cross section calculated by equations 25 and 41 56 


\section{CONVERSION FACTORS}

For the convenience of readers who may want to use inch-pound units rather than metric (International System) units, the data may be converted by using the following factors:

Multiply metric units

millimeter $(\mathrm{mm})$

meter $(m)$

kilometer $(\mathrm{km})$

square meter $\left(\mathrm{m}^{2}\right)$

cubic meter $\left(m^{3}\right)$

kilogram $(\mathrm{kg})$

meter per second $\left(\mathrm{m} \mathrm{s}^{-1}\right)$

kilopascal $(\mathrm{kPa})$ by

0.03937

3.281

0.6214

10.76

35.31

2.205

2.237

0.145
To obtain inch-pound units

inch (in)

foot ( $f t)$

mile (mi)

square foot $\left(\mathrm{ft}^{2}\right)$

cubic foot $\left(\mathrm{ft}^{3}\right)$

pound ( $1 \mathrm{~b}$ )

mile per hour (mph)

pound per square inch $\left(1 \mathrm{~b}\right.$ in $\left.^{-2}\right)$

Temperature in degrees Celsius $\left({ }^{\circ} \mathrm{C}\right)$ can be converted to degrees Fahrenheit $\left({ }^{\circ} \mathrm{F}\right)$ as follows:

$$
{ }^{\circ} \mathrm{F}=32+\frac{9}{5}{ }^{\circ} \mathrm{C}
$$




\section{ASSESSMENT OF A STEADY-STATE PROPANE-GAS TRACER METHOD}

FOR DETERMINING REAERATION COEFFICIENTS, CHENANGO RIVER, NEW YORK by N. Yotsukura, D. A. Stedfast, and G. H. Jirkal/

\section{ABSTRACT}

A test was conducted in a meandering 9.6 -kilometer reach of the the Chenango River near Binghamton, New York, to assess the feasibility of a two-dimensional propane-gas tracer method as a means of estimating in situ reaeration coefficients in a wide river.

The two-dimensional steady-state tracer method is based on the principle of superposition and is applicable to a linear transport problem in a steady, nonuniform, open-channel flow. The method is an extension of an earlier one-dimensional method and utilizes a new concept of measuring gas desorption between the upstream and downstream stations along a depth-averaged streamline. An approximate method is also introduced for estimating wind effects on gas desorption from the measurement of temporal variation of tracer concentration at a single station.

It is concluded from the field test that the method is feasible for the determination of gas desorption coefficients and wind effects in a wide river. The calculated results are consistent with those obtained from the onedimensional method and with results cited in recent literature. This test of the method is the first of its type in riverine environments; however, the planning and execution of the test require some modifications and, thus, the method does not appear to be ready for immediate operational applications.

1/ Professor, School of Civil and Environmental Engineering, Cornell University, Ithaca, New York 


\section{INTRODUCTION}

\section{Background}

This is the second report on field assessment of the hydrocarbon gas tracer method for estimating in situ reaeration coefficients in natural rivers. The study has been conducted since April, 1981, jointly by Cornell University, the New York Department of Environmental Conservation, and the U.S. Geological Survey.

The report by Yotsukura and others (1983), henceforth called the first report, developed and tested the steady-state method for determining the desorption coefficient of dissolved propane-gas tracer from measurement in a one-dimensional tracer plume, in which tracer concentration is uniform in a cross section and varies only in the longitudinal direction. Three tests conducted in a 5.2-km reach of the Cowaselon Creek, New York, demonstrated that the method is operationally feasible and that the reproducibility of tracer data is excellent.

The one-dimensional method, although it serves most of the current need for one-dimensional modeling of dissolved oxygen in small rivers, is not operationally suitable for a wide river, where a long distance from the tracer injection site--for example, $20 \mathrm{~km}$--may be necessary for the beginning of one-dimensional plume. For such a river, it is desirable to develop a method which enables the measurement of gas desorption in a two-dimensional plume, in which tracer concentration is uniform only in the vertical direction and varies in transverse and longitudinal directions. From well-established knowledge of the hydraulics of mixing in nonstratified rivers, such a two-dimensional plume is always located 
upstream of the one-dimensional plume and may be obtained at a distance of 50 to 100 times the stream depth from the injection site (Yotsukura and Sayre, 1976).

Another incentive for developing the two-dimensional method is that wide rivers offer a better environment than narrow rivers for evaluating effects of wind on gas desorption; winds at the surface of a wide river are less attenuated by the sheltering of high banks or vegetation and, thus, tend to be more variable than those of a narrow river. Even though the effect of wind shear on gas exchange has been studied extensively in laboratories and open oceans, this effect has long been neglected in riverine environments, where the assumption has been that the turbulence for gas exchange is solely generated by the channel flow (Jirka and Brutsaert, 1984).

Based on the conclusion of the first report, the measurement with a steady-state tracer plume was considered desirable, and the basic techniques employed in the one-dimensional method were extended to the two-dimensional plume with a new concept of measuring gas desorption along streamlines. In preparation for field testing of the method, several visits to potential test sites were made in an effort to find a river having a width larger than $60 \mathrm{~m}$, good wind exposure, a small channel bottom slope, and a relatively high flow velocity. Wadability, accessibility, and absence of river traffic were other important considerations. All of the above requirements were satisfied, except for the channel slope, at a $9.6-\mathrm{km}$ reach of the Chenango River near Binghamton, New York. The map of this field test site is shown in figure 1 . 


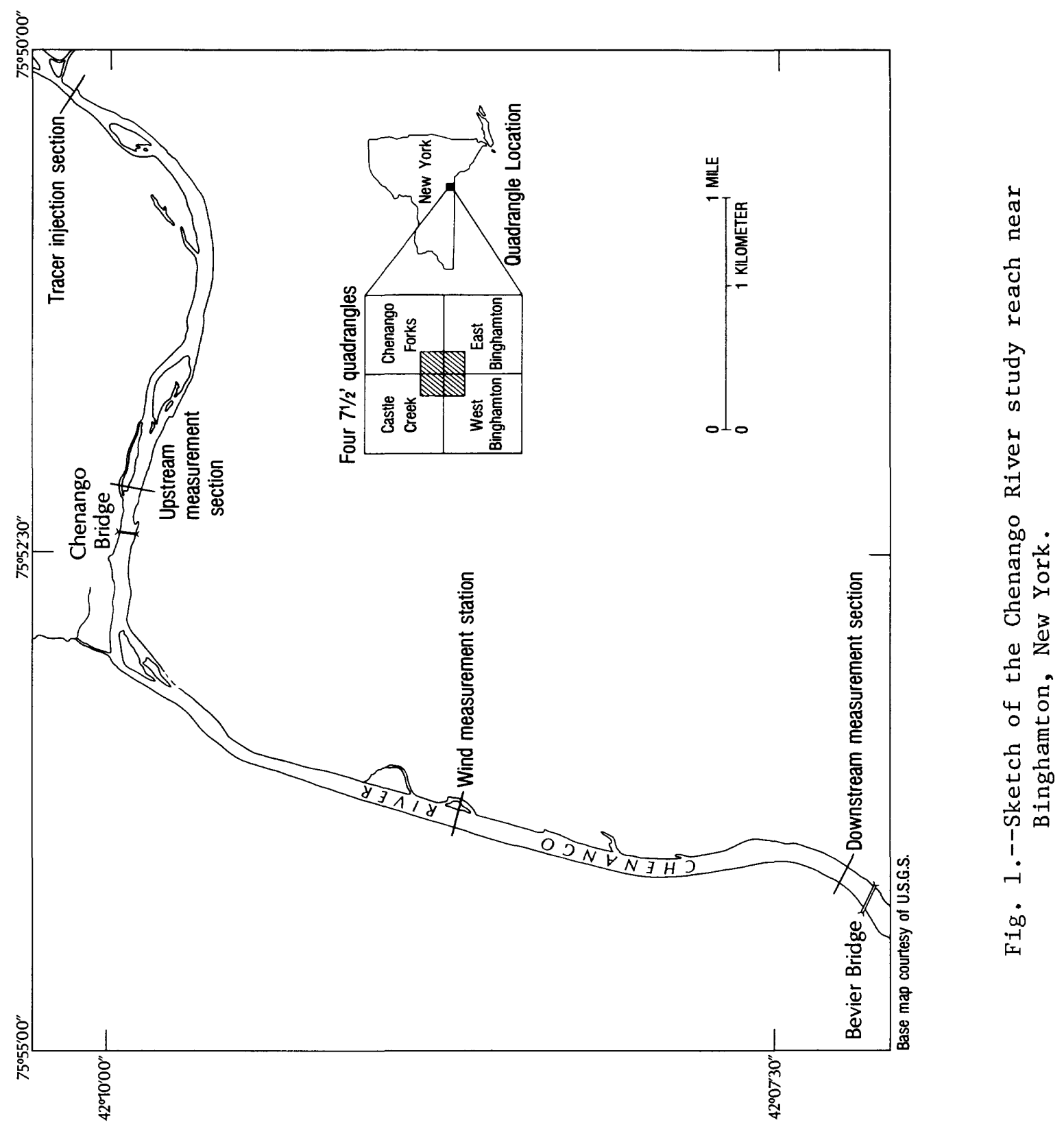


Following the format of the first report, this report is also devoted to the field methodologies for determining the desorption coefficient of dissolved propane-gas tracer in a natural river. The conversion of gas desorption coefficients to estimated reaeration coefficients by a conversion factor is outside the scope of the report. Laboratory assessment of the hydrocarbon-gas tracer method is currently being conducted at the University of Texas at Austin. As part of this study, the conversion factor is being investigated by use of mixing tanks and a recirculating flume (Rainwater and Holley, 1984).

\section{Purpose and Scope}

The purpose of the report is to describe the development and testing of the two-dimensional steady-state method for determining the propane-gas desorption coefficient in a wide natural river. The study is the second phase of field assessment of the hydrocarbon gas tracer method for reaeration coefficients. The assessment is based on a 24 -hour field test conducted in a $9.6-\mathrm{km}$ reach of the Chenango River near Binghamton, New York, on August 4-5, 1982. 


\section{Acknowledgments}

The authors would like to acknowledge W. H. Brutsaert, R. E. Draper, E. R. Holley, and R. E. Rathbun for their technical advice and consultation. The field test was conducted by personnel of the U. S. Geological Survey, the New York Department of Environmental Conservation, and Cornell University. E. R. Holley and J. D. Bales of the University of Texas also participated in the field test.

\section{EQUATIONS FOR DISSOLVED GAS CONCENTRATION}

Derivation of the two-dimensional steady-state equations for dissolved gas concentration will be based on similar assumptions and techniques as used in the one-dimensional method described in the first report. Thus, the following derivation will not duplicate some background and details, which were explained in depth in the first report.

Assume that a neutrally buoyant mixture of a dissolved gas tracer and a hypothetical conservative tracer is injected into a steady channel flow as an instantaneous source and that the tracer clouds are observed at a downstream location, where the tracer concentration is essentially uniform over the flow depth. In this two-dimensional tracer cloud, the concentration of the nonconservative gas tracer may be related to that of the conservative tracer (Tsivoglou and others, 1965; Holley and Yotsukura, 1984) by 


$$
c(x, z, t)=\frac{M}{M_{c}} C_{c}(x, z, t) \exp (-K t),
$$

where $C$ and $M$ designate the concentration and initial mass of tracer, respectively, and the subscript c denotes the conservative tracer. The notation $\mathrm{K}$ designates the gas desorption coefficient. The coordinate $\mathrm{x}$ is measured downstream from the injection site, the $z$ coordinate designates the transverse distance, and $t$ is time measured from the instant of injection.

Assumptions involved in eq. 1 are as follows: (1) the surface desorption of gas tracer can be treated as a first-order decay process because the concentration is vertically uniform, (2) the advection and mixing of both tracers are identical, (3) a linear relation exists between the concentration and initial mass of tracers, and (4) $\mathrm{K}$ is constant in the sense that it is an averaged value over a finite time interval, $t$.

In dealing with two-dimensional solute transport in a nonuniform steady flow, it is known that the cumulative discharge, $q$, is a much better transverse coordinate than the transverse distance, 2 (Yotsukura and Sayre, 1976). The cumulative discharge is defined by

$$
q=\int_{0}^{z} h(x, z) u(x, z) d z
$$

where $h$ and $u$ are the depth and the depth-averaged velocity, respectively, and both are functions of $\mathrm{x}$ and $\mathrm{z}$. 
The cumulative discharge, defined along any cross section of discharge measurement, is zero at one bank and becomes equal to $Q$, the total discharge of the river, at the other bank. The calculation of $q$ is similar to the process of summation of subdischarges, which is a routine in any stream gaging work, and the plot of $q$ against $z$ at a cross section establishes the one-to-one relationship between the two transverse coordinates. Furthermore, a longitudinal curve along which q remains constant defines the depth-averaged two-dimensional streamline. Switching the transverse coordinate from $z$ to $q$, eq. 1 is rewritten as

$$
C(x, q, t)=\frac{M}{M_{c}} C_{c}(x, q, t) \exp (-K t)
$$

As a step toward the derivation of a steady-state equation from eq. 3 , the normalized response function, $f$, will be defined as

$$
f(x, q, t)=\frac{c_{c}(x, q, t)}{\int_{0}^{\infty} c_{c}(x, q, t) d t}
$$

It is clear from eq. 4 that $\int_{0}^{\infty} f d t=1$ and $f$ has the dimension of time ${ }^{-1}$. In a two-dimensional tracer cloud, however, the integral of eq. $4, \int_{0}^{\infty} c_{c} d t$ is an expression of tracer mass passing by the location $(x, q)$ and thus is variable in a cross section. This variability will be accounted for by defining the mass distribution factor, $\phi$, as

$$
\phi(x, q)=\frac{Q \int_{0}^{\infty} c_{c}(x, q, t) d t}{\int_{0}^{Q} \int_{0}^{\infty}{ }_{c}(x, q, t) d t d q}
$$


As for the double integral of eq. 5, however, the mass conservation requires that

$$
\int_{0}^{Q} \int_{0}^{\infty} c_{c}(x, q, t) d t d q=M_{c}
$$

Note that the formulation of eq. 5 is made such that $\phi$ is the nondimensional parameter. The value of $\phi$ reduces to unity for the one-dimensional plume where $\int_{0}^{\infty} \mathrm{C}_{c} \mathrm{dt}$ is uniform in a cross section. Also note that $\int_{0}^{Q} \phi d q=Q$. Substituting eqs. 4, 5, and 6 into eq. 3, the latter is transformed to

$$
C(x, q, t)=\frac{M}{Q} \phi(x, q) f(x, q, t) \exp (-K t)
$$

When the gas tracer is injected continuously at a constant mass inflow rate, $m$, the resulting concentration may be obtained by applying the principle of superposition for solute transport (Wylie, 1951; Taylor, 1959). Denote $\tau$ as the time of tracer injection having the same origin as $t$ and $\tau_{I}$ as the duration of continuous injection. A continuous injection may be considered as consisting of an infinite number of sequential instantaneous injections with $\mathrm{md} \tau=\mathrm{M}$. The superposition of eq. 7 on the basis of the steadiness of channel flow is given (Yotsukura and Kilpatrick, 1973) by

$$
C(x, q, t)=\frac{m}{Q} \phi(x, q) \int_{0}^{\tau} I f(x, q, t-\tau) \exp \{-K(t-\tau)\} d \tau
$$

Changing the variable of integration from $\tau$ to $p=t-\tau$, where $p$ has the same origin as $t$ and $\tau$, eq. 8 is reduced to 


$$
C(x, q, t)=\frac{m}{Q} \phi(x, q) \int_{t-\tau}^{t} f(x, q, p) \exp (-K p) d p
$$

On the basis of eq. 9, it is possible to determine the values of $t$ and $\tau_{I}$ necessary for obtaining steady-state gas concentrations. For a given location $(x, q)$, however, the quantities within the integral of eq. 9 can be regarded as the sole function of time, and the detailed explanation given in the first report on the conditions for steady-state gas concentration applies equally well to the present situation. Briefly, the steady-state gas concentration will start at the time, $t_{D}(x, q)$, and last until the time, $\tau_{I}+t_{A}(x, q)$, where $t_{A}$ and $t_{D}$ designate the time of the arrival of leading edge and the time of departure of the trailing edge, respectively, of the tracer cloud observed at $(x, q)$ following an instantaneous injection at $t=0$. Therefore, the injection duration, $\tau_{I}$, must be longer than the cloud duration, $t_{D}-t_{A}$, in order to obtain a steady-state concentration at the location $(x, q)$.

For convenience, the steady-state gas concentration will be denoted by

$$
C(x, q)=\frac{m}{Q(x)} \phi(x, q) \int_{0}^{\infty} f(x, q, p) \exp (-K p) d p
$$

which is obtained by simultaneously increasing $t$ and $\tau_{I}$ to infinity in eq. 9. In eq. 10, the total river discharge $Q$ is shown to be a function of $x$. This notation should be interpreted in a limited sense, namely, that $Q$ must be independent of time but may increase in the downstream direction so long as the increase 1 mains gradual and small so that application of the principle of superpo: on is valid. 
The form of eq. 10 is not very convenient for use in the field because of the integral involving $k$. Before going further, however, note that the time variable, p, of eq. 10 can be replaced by the more familiar notation, $t$, without losing generality of the discussion. Also, for a given location $(x, q)$, the normalized response unction, $f$, may be considered as the sole function of time, $t$. With these adjustments, one now seeks to reduce the integral of eq. 10 to a more tractable form, which is expected to contain the term, $\exp (-K \bar{t})$ with $\bar{t}$ being the mean travel time, based on the conclusions obtained in the first report.

By definition of eq. 4 for the normalized response function, the zeroth-order moment of $f(t)$ is unity and the first-order moment of $f(t)$ defines the mean travel time $\bar{t}$, namely,

$$
\int_{0}^{\infty} f(t) d t=1 \text { and } \int_{0}^{\infty} t f(t) d t=\bar{t}
$$

Utilizing the above properties of $f(t)$, assuming $K$ constant, and expanding the exponential function by means of a Taylor series,

$$
\int_{0}^{\infty} f(t) \exp (-K t) d t-\exp (-K \bar{t})=\sum_{n=2}^{\infty} \frac{(-1)^{n} K^{n}}{n !}\left[\int_{0}^{\infty} t^{n} f(t) d t-(\bar{t})^{n}\right]
$$

By some involved manipulations, the right-hand side of eq. 12 can be shown to be

$$
\sum_{n=2}^{\infty} \frac{(-1)^{n} k^{n}}{n !}\left[\int_{0}^{\infty} t^{n} f(t) d t-(\bar{t})^{n}\right]=\exp (-k \bar{t}) \sum_{n=2}^{\infty} \frac{(-1)^{n} k^{n}}{n !} \int_{0}^{\infty}(t-\bar{t})^{n} f(t) d t
$$

Substituting eq. 13 back into eq. 12 ,

$$
\int_{0}^{\infty} f(t) \exp (-K t) d t=\exp (-K \bar{t})\left[1+\sum_{n=2}^{\infty} \frac{(-1)^{n} K^{n}}{n !} \int_{0}^{\infty}(t-\bar{t})^{n} f(t) d t\right]
$$


Designating the bracketed term of eq. 14 as the correction factor, E, reverting back to the notation $f(x, q, t)$, and substituting eq. 14 into eq. 10, the latter is reduced to

$$
C(x, q)=\frac{m}{Q(x)} \phi(x, q) E(x, q) \exp [-K \bar{t}(x, q)]
$$

where

$$
E(x, q)=1+\sum_{n=2}^{\infty} \frac{(-1)^{n} K^{n}}{n !} \int_{0}^{\infty}[t-\bar{t}(x, q)]^{n} f(x, q, t) d t
$$

Eq. 15 is the equation for the two-dimensional steady-state gas concentration to be used in the calculation of $\mathrm{K}$. Because the summation term of eq. 16 is expected to be very small relative to unity for a typical form of $f(x, q, t)$, the first calculation by eq. 15 may be made by assuming $E=1$ and more accurate calculations can be made with successive corrections by means of eq. 16 .

In the first report, the one-dimensional steady-state gas concentration was expressed as

$$
C(x)=\frac{m}{Q} \exp \left(-K \frac{x}{U}\right)
$$

which is an approximate solution for a straight prismatic channel on the condition that

$$
\frac{4 D_{x} K}{U^{2}}<1
$$


where $D_{x}$ is the longitudinal dispersion coefficient and $U$ is the velocity (Fischer, 1973). Eq. 15 for the one-dimensional plume with $\phi=1$ reduces to eq. 17 approximately, when the summation term of eq. 16 is much smaller than unity. Thus, eq. 16, not requiring the assumption of a prismatic channel, specifies a more general condition than the relation 18 required for eq. 17 to be the approximate steady-state solution.

In considering field application of eqs. 15 and 16, it is convenient to introduce an auxiliary notation system for the independent variables, $x$ and $q$, as the desorption coefficients in this study will be measured in a two-dimensional sense. In the following discussion, the subscripts, $u$ and $\mathrm{d}$, will be used to designate upstream and downstream cross section, respectively. The distances to these sections are $x_{u}$ and $x_{d}$ from the tracer injection location. As for the transverse location, the superscript, $r=100 \mathrm{q} / \mathrm{Q}$, will be used as the streamline index expressed as the percentage of the total river discharge. Eq. 15 is thus written for upstream and downstream measurement locations, respectively, as

$$
C_{u}^{r}=\frac{m}{Q_{u}} \phi_{u}^{r} E_{u}^{r} \exp \left(-K_{u} \bar{t}_{u}^{r}\right)
$$

and

$$
C_{d}^{r}=\frac{m}{Q_{d}} \phi_{d}^{r} E_{d}^{r} \exp \left(-K_{d} E_{d}^{r}\right)
$$

Because the measurement of gas inflow rate, $m$, is not practical in a field test, eqs. 19 and 20 may be combined to eliminate m. Assume, for this purpose, that the upstream and downstream measurement locations are on the same streamline and that

$$
k_{d} t_{d}^{-r}-k_{u} t_{u}^{r}=k^{r}\left(t_{d}^{r}-t_{u}^{-r}\right)
$$


In formulating eq. 21, one considers that, if the tracer source streamline, $r_{s}$, is not the same as the measurement streamline, $r$, then $K_{u}$ and $\mathrm{K}_{\mathrm{d}}$ of eqs. 19 and 20 do not represent the desorption along $r$. However, the difference of desorption expressed by the left side of eq. 21 will represent the desorption along the streamline, $r$, and thus can be expressed by means of the desorption coefficient $k^{r}$ on the right side of eq. 21. Combining eqs. 19, 20, and 21 , one obtains

$$
\frac{C_{u}^{r} Q_{u} \phi_{d}^{r} E_{d}^{r}}{C_{d}^{r} Q_{d} \phi_{u}^{r} E_{u}^{r}}=\exp \left[K^{r}\left(t_{d}^{r}-E_{u}^{-r}\right)\right]
$$

Eq. 22 will be used as the field equation for calculation of $\mathrm{K}^{\mathrm{r}}$ from steady-state concentrations of propane-gas observed along the steamline $r$. The quantities, $\phi$ and $\bar{t}$, are calculated from the data of conservative tracer cloud by means of eqs. 5 and 11 , respectively. The calculation of E by eq. 16 is a repetitive process as mentioned previously because it requires not only tracer cloud data but also $K$ values. Note also that eq. 22 with $\phi=1$ and without the superscript $r$ can be used for the onedimensional plume. Because of the generality of the E term given by eq. 16, eq. 22 supersedes the steady-state field equations presented in the first report.

In utilizing steady-state equations for field applications, final consideration must be given to the condition of steady-state under variable and high wind speeds. When the channel flow is steady and the wind speed is negligible, $\mathrm{C}(\mathrm{x}, \mathrm{q})$ of eq. 15 is constant regardless of the time of gas sampling, and the calculated $K$ represents the gas desorption generated solely by the channel flow turbulence. Under windy conditions, however, the desorption generated by wind shear turbulence may become a significant 
component of the total desorption coefficient. On the other hand, because such a natural wind speed can not be expected to remain steady during the required period for tracer superposition under a continuous injection, the absolute steadiness of both water and air flows, which is required for eq. 15 to be valid under windy conditions, will never be realized in field conditions.

In order to make eq. 15 suitable for the space and time scales of field tests, the condition of steady-state for wind speeds may be considered on the basis of averaged wind speeds utilizing different time intervals of averaging. Assume that variable and high winds will not change those parameters related to tracer mixing, in particular the form of the normalized response function, $f(x, q, t)$. According to eq. 14, then, one may assume that the residence time of the average particle in a superposed tracer plume will be equal to $\bar{t}(x, q)$ even under such wind conditions. The steady-state condition for air flow will be assumed by a constancy of the wind speed, $\bar{U}_{a}$, averaged over the mean travel time, $\bar{t}$,

$$
\bar{u}_{a}\left(x, q, t_{s}\right)=\frac{1}{\bar{t}} \int_{t_{s}-\bar{t}}^{t} s \quad v_{a}(x, q, t) d t
$$

where $t_{s}$ is the time of gas sampling and $U_{a}$ designates the instantaneous wind speed.

As for the increased gas desorption due to $\bar{U}_{a}$, an empirical wind function, $\psi$, may be defined as follows.

$$
K=K_{c}+\psi
$$


where $\mathrm{K}$ represents the total gas desorption coefficient, $\mathrm{K}_{c}$ is the desorption coefficient generated by the steady channel flow turbulence, and $\psi$ is such that it is zero when $\bar{U}_{a}$ is low and finite when $\overline{\mathrm{U}}_{\mathrm{a}}$ is high. Though $\psi$ has the dimension of a gas desorption coefficient, it is not a direct expression of wind generated gas desorption coefficient. This empirical approach is necessary in view of the current lack of detailed knowledge on the composite effect of channel and wind generated turbulences on gas desorption (Plate and Friedrich, 1984).

With the above considerations and assuming that $\mathrm{E}(\mathrm{x}, \mathrm{q})$ is not influenced by wind, only $\mathrm{C}(\mathrm{x}, \mathrm{q})$ and $\mathrm{K}$ of eq. 15 will be affected by wind and become gradually varying functions of $\bar{U}_{a}$, and thus, of gas sampling time, $t_{s}$. Eq. 15 now may be modified for windy conditions as

$$
C\left(x, q, t_{s}\right)=\frac{m}{Q(x)} \phi(x, q) E(x, q) \exp \left[-\left\{k_{c}(x, q)+\psi\left(x, q, t_{s}\right)\right\} \bar{t}(x, q)\right]
$$

A similar time dependence should be expected for the C's and $K^{\prime} s$ of eqs. 19,20 , and 22 , even though the forms of these equations remain unchanged. A relation similar to eq. 21 will be assumed independently for $K_{c}$ and $\psi$.

From the definition of $\psi$, eq. 15' may be exploited for a direct evaluation of $\psi$ as follows. Suppose at a given location $(x, q)$ that two measurements are made at $t_{H}$ and $t_{L}$, when $\bar{U}_{a}\left(t_{H}\right)$ is high and effective in increasing the gas desorption above the level of $K_{c}$ while $\bar{U}_{a}\left(t_{L}\right)$ is low so that $\psi\left(t_{L}\right)$ is zero. Writing eq. 15' for these two sampling times and assuming that $m, Q, \phi, E, K_{c}$, and $\bar{E}$ are constant at this location, one obtains 


$$
\frac{C\left(t_{L}\right)}{C\left(t_{H}\right)}=\exp \left[\psi\left(t_{H}\right) \bar{t}\right]
$$

The above method is devised by substituting the constant value of $\bar{U}_{a}\left(t_{s}\right)$ for the instantaneous wind speed $U_{a}(t)$ for the steady-state equation. Because such an averaged wind speed not only disregards the variability of $U_{a}(t)$ but also may vary with the length of averaging time, one can not expect that the variation of $\psi$ with $\overline{\mathrm{U}}_{\mathrm{a}}$ would be a direct description of the wind-generated gas desorption. However, one can obtain an empirical information on the relation of $\psi$ and $\bar{U}_{a}$, which may be useful for practical purposes. Apparently this kind of measurement has never been carried out in an open channel flow of large dimension.

\section{DESCRIPTION OF FIELD TEST \\ Planning of Test}

The two-dimensional steady-state method, as does the one-dimensional method, utilizes two tracers...that is, an instantaneous injection of rhodamine WT dye is combined with a long-duration injection of propane gas. However, the two-dimensional method requires a much more elaborate test planning than the one-dimensional one as described below.

After a couple of visits to the Chenango River, the tracer injection site was established near Port Crane shown in figure 1; at this location, the left bank provided firm and accessible ground for installing the tracer injection equipments. This provided a suitable downstream reach of approximately $10 \mathrm{~km}$ without entering an impounded area above the con- 
fluence of the Chenango River with the Susquehanna River. Low velocity and unwadable depth of the impounded area were considered undesirable for the first test of the feasibility of the two-dimensional plume method. The bulk flow parameters in the reach were estimated as follows. Assuming the target river discharge, $Q$, at $14 \mathrm{~m}^{3} \mathrm{sec}^{-1}$, the average depth, $H$, was $0.4 \mathrm{~m}$, the average velocity, $U$, was $0.34 \mathrm{~m} \mathrm{sec}^{-1}$, the channel slope, $\mathrm{S}$, was 0.0008 , and the average width, $W$, was $100 \mathrm{~m}$. These values were used for planning purposes only and should not be confused with measured values quoted later.

The detailed planning began with the choice of measurement streamlines. Three streamlines of $\mathrm{r}=10,30$, and 50 percent were chosen primarily because of interest in observing the variation of gas desorption between the 10 percent streamline, which supposedly represents shallow slow-moving part near the bank, and the 50 percent streamline, which represents the deep, fast-moving midstream part. These measurements along the left half of the channel was considered adequate in characterizing the entire cross section. Choosing the injection streamline at $\boldsymbol{r}_{\mathbf{s}}=30$ percent, the next step was to ensure that the tracer concentration was high enough for measurement at three streamlines of the upstream cross section. Assuming low values for the transverse mixing coefficient and utilizing the estimated bulk flow parameters, the two-dimensional steadystate concentration in terms of the mass distribution factor, $\phi$, was estimated by means of the stream-tube analytical model (Yotsukura and Cobb, 1972).

The third step was to ensure that the distance, $x_{d}-x_{u}$, was long enough so that the nondimensional number, $k^{r}\left(t_{d}^{-r}-t_{u}^{r}\right)$, was highter than 0.5 for an estimated range of $\mathrm{K}^{\mathrm{I}}$ between 0.10 and $0.15 \mathrm{hr}^{-1}$. This value of 0.5 was certainly not satsifactory from the viewpoint of error 
propagation described in the first report; however, use of this value was considered an acceptable risk because, on the other hand, the wind effect measurement could benefit more from smaller values of the mean travel time, $\bar{t}_{d}^{r}-t_{u}^{r}$, between the two cross sections.

Out of these estimations, the upstream cross section was established at $3.2 \mathrm{~km}$ downstream of the injection site and upstream of the Chenango Bridge (figure 1). The mass distribution factor was estimated as $\phi_{u}^{10}=$ $0.66, \phi_{u}^{30}=3.72$, and $\phi_{u}^{50}=0.65$. The downstream cross section was to be $6.4 \mathrm{~km}$ downstream of the upstream cross section and upstream of the Bevier Bridge (figure 1), where the estimation was that $\phi_{d}^{10}=1.41, \phi_{d}^{30}=2.17$, and $\phi_{\mathrm{d}}^{50}=1.20$. The gas injection rate was first estimated from eq. 20 to ensure that $\mathrm{C}_{\mathrm{d}}^{50}$ was at least $2 \mu \mathrm{g} \mathrm{L}^{-1}$ (microgram per liter) and then adjusted based on gas injection records of the Cowaselon Creek tests described in the first report.

At the final stage of planning, it was felt that the steady-state dye plume might provide an easier and more accurate means of measuring the mass distribution factor, $\phi$, than the transient dye cloud resulting from an instantaneous injection. Because $\phi$ was a crucial but untested parameter for a two-dimensional plume, additional investment in equipment and manpower for continuous dye injection appeared to be worth the cost. Thus the final plan was to start continuous injections of gas and dye simultaneously. The gas injection was to last 24 hours to measure the effect of wind by taking advantage of diurnal wind speed variations, whereas the dye injection was to last long enough to obtain steady-state dye concen 
tration at all measurement locations. A separate instantaneous dye injection, which was needed for the measurement of mean travel time and normalized response function, was to be made later in the test when there was no interference of dye concentrations resulting from the earlier injection.

\section{Preliminary Dye Test, Aug. 3, 1982}

In order to find the required time length for continuous injections of tracers and to obtain overall ideas about the travel time and mixing, a preliminary dye test was conducted on Aug. 3, 1982. Two liters of rhoda-mine WT 20-percent solution was instantaneously released at 10:50 am at about $34 \mathrm{~m}$ from the left edge of water at the injection site. Water samples were collected at a midstream location of the upstream section between 1:00 pm and 4:00 pm. At the downstream section, samples were collected at midstream and near the left edge of water beginning at 5:00 $\mathrm{pm}$ and ending at 10:00 $\mathrm{pm}$. In situ reading of dye concentration with the fluorometer indicated that the dye concentration near the left bank at the downstream section at 10:00 pm was $1.1 \mu \mathrm{g} \mathrm{L}^{-1}$ which was about 16 percent of the peak concentration of $6.7 \mathrm{\mu g} \mathrm{L}^{-1}$ observed at $6: 40 \mathrm{pm}$. Knowing that the leading edge of dye cloud arrived at this location at 5:20 pm, the dye cloud duration was estimated to be about 8 hours. The dye cloud data also confirmed that tracer concentrations would be high enough at all measurement locations; these data were useful in the final scheduling of crew assignments. 
Discharge measurements at the three cross sections were conducted independently of the dye test on Aug. 3, 1983. By using the definition of eq. 2, a plot of cumulative discharge, $q$, against the transverse distance, $z$, was prepared for each cross section. At the injection site, the source location was established at $32.6 \mathrm{~m}$ from the left edge of water and represented the 30 percent streamline. At the two measurement cross sections, the river discharge, $Q$, was divided into 10 equal subdischarges and distances from the left bank of the nine streamlines, $r=10, \ldots 90$ percent, were determined from the $q$ versus $z$ plot. The injection location and 18 measurement locations were then marked in the field by securing concrete blocks with buoys firmly on the channel bed. In addition, the tag line was left suspended at the injection site to support tracer supply lines from the left bank.

\section{Main Tracer Test, Aug. 4-5, 1982}

The continuous injections of propane gas and rhodamine WT dye were started at 8:30 am, Aug. 4, 1982. Three 45-kg propane tanks were placed on the left bank to supply three sets of gas diffusers for the 24-hour test duration. All diffusers were of the flat-plate porous-tile type with a 2-micron pore size. Two diffusers of 1 meter length were tied side by side as a set to receive gas supply from one propane tank. The three diffuser sets were then anchored to the channel bottom in series to form a source configuration of approximately $0.5 \mathrm{~m}$ in width and $3 \mathrm{~m}$ in length in the direction of channel flow. The volumetric flow rate at the tank was 
set at $30 \mathrm{~L} \mathrm{~min}^{-1}$ and the line pressure at $207 \mathrm{kPa}$ (kilopascal). Note that the flow rate at the tank is not the tracer mass inflow rate, $\mathrm{m}$, because only 10 to 20 percent of the injected gas dissolved in the water.

The gas flow rate from the first tank was very steady throughout the test period according to the half-hourly reading of flow rate and line pressure gauges. The flow rates of the second and third tanks were not as steady as the first. The line pressure of both tanks went down to 172 to $186 \mathrm{kPa}$ between 1:00 pm and 6:45 pm, Aug. 4. The line pressure of the second tank dropped to $179 \mathrm{kPa}$ again at 3:00 am, Aug. 5, indicating the end of gas supply. The second tank was replaced with a 9-kg tank with fresh supply. The third tank was also replaced with a 9-kg fresh tank at 3:45 am, Aug. 5, as the line pressure went down to $172 \mathrm{kPa}$. The propane gas injection was terminated at 7:00 am, Aug. 5, for all tanks. However, the effective duration of continuous injection was estimated to be $21.1 \mathrm{hr}$ between $8: 30 \mathrm{am}$, Aug. 4 and 5:36 am, Aug. 5 .

A small battery-operated pump connected to a $20 \mathrm{~L}$ tank located on the left bank supplied the dye line with a volumetric flow rate of $260 \mathrm{~mL}$ $\min ^{-1}$ of diluted dye solution. This diluted solution was prepared in the field by manually mixing $2 \mathrm{~L}$ of rhodamine WT 20-percent solution with $18 \mathrm{~L}$ of river water in a 20-L tank. At the injection location, the dye line was tied to the upstream end of the gas diffusers and the open end was submerged to mid-depth. As one tankful of dye solution was emptied, the pump was switched to another tank within a few seconds. In this manner, approximately $160 \mathrm{~L}$ of diluted dye solution was released into the reach during the 9-hour injection period which ended at 5:30 pm, Aug. 4 . 
The continuous dye injection was interrupted three times at 9:00 am, 10:50 am, and 2:00 pm, Aug. 4. These interruptions were visually noted by the disappearance of red dye stream at the injection location. Because two direct measurements of the volumetric flow rate at $9: 10$ am and 12:30 $\mathrm{pm}$ were 260 and $265 \mathrm{~mL} \mathrm{~min}^{-1}$, respectively, the injection crew assumed that the supply rate was steady and the interruptions were brief. Each interruption was repaired easily by switching the dye tank, tapping the supply line, or shaking the dye tank.

The sampling of propane gas concentration at the three streamline locations, $r=10,30$, and 50 , of the upstream section started at 2:00 pm, Aug. 4, and lasted until 7:40 am, Aug. 5. Similar sampling at the downstream section began at 6:00 pm, Aug. 4, and ended at 11:30 am, Aug. 5. A water sample was collected at 30 -minute intervals in a $40-\mathrm{mL}$ septum cap vial placed in a dissolved gas sampler and was processed following the instructions given by Rathbun (1979). The beginning of gas sampling was dictated by manpower requirements and was not intended to match the beginning of steady-state gas plumes.

The sampling of dye concentration at the 11 streamline locations-$\mathbf{r}=0,10, \ldots 90$, and 100 percent--at the upstream cross section started at $12: 45 \mathrm{pm}$ and lasted until $8: 20 \mathrm{pm}$, Aug. 4. Similar sampling at the downstream section was started at $5: 45 \mathrm{pm}$ but had to be terminated at 9:00 pm, Aug. 4, when it was discovered that dye sample vials were in short supply. It was clear that the steady-state dye concentration was not obtained in areas near the banks, where the preliminary dye test indicated that the cloud duration was almost 8 hours. All dye samples were collected at 30 -minute intervals by use of $30-\mathrm{mL}$ glass vials. In addition to the above sampling which was aimed at obtaining steady-state 
dye concentration, dye samples were also collected at five streamlines--r $=10,30,50,70$, and 90 percent--between 10:30 am and 12:45 pm at the upstream section and between $2: 40 \mathrm{pm}$ and 5:45 pm at the downstream section. The additional samples were intended to supplement the steadystate dye data so that the principle of linear superposition could be demonstrated with field data.

At 6:00 am, Aug. 5, 3 liters of rhodamine WT 20-percent solution were instantaneously released at the injection location to measure the mean travel time and normalized response function. Dye concentration sampling was restricted to the three streamline locations--r $=10,30$, and 50 percent--at two cross sections. At the upstream section, the sampling was made at 10-minute intervals from 7:30 am to 10:55 am, Aug. 5. The downstream section sampling was from $11: 45$ am to $6: 30 \mathrm{pm}$, Aug. 5 .

Stage and water temperature measurements were made at the left bank of the injection site at 30-minutes intervals and also at the wind measurement station described later. Because the stage change was insignificant throughout the test period, no additional discharge measurement was made on Aug. 4-5, 1983; thus the gaging data of Aug. 3 were the sole discharge data for the entire test.

Wind measurements were made at a station located about $2.7 \mathrm{~km}$ upstream of the downstream section, as shown in figure 1. The instruments used for this purpose were cup anemometers that had been calibrated in a wind tunnel. The five anemometers were deployed on four masts that were stationed on or near a sand bank island in the river. The approximate geometry of the sand bank, which had a maximum elevation of about $0.3 \mathrm{~m}$ above 
the water surface and was covered with grassy vegetation, is shown in figure 2. The left and the right banks were overgrown with bushes and about $30 \mathrm{~m}$ inland by trees 15 to $25 \mathrm{~m}$ in height.

The tall mast (TM) was installed about $3 \mathrm{~m}$ from the upstream tip of the island and bore two anemometers--one at $6.30 \mathrm{~m}$ (WI) and another at $3.18 \mathrm{~m}$ (W2) above the water surface--to monitor the prevailing wind field. Each of three small masts (SMI, SM2, and SM3) that were installed in the water surrounding the sand bank supported one anemometer (W3, W4, W5, respectively) at $0.34 \mathrm{~m}$ above the water surface; these anemometers measured the wind speed directly above the water. The wind direction was measured by wind vanes on TM and SM2. In addition to these wind data, dry- and wet-bulb air temperatures and water temperature were measured. All measurements were recorded at approximately 0.5 -hour intervals. It should be noted that the cup anemometer reading represents a cumulative count over the preceding interval.

\section{DATA AND ANALYSIS}

The first two sections of this chapter present two sets of dye data and calculation of the mixing parameters, $\bar{t}, E$, and $\phi$ of the steadystate equations. The third section presents the wind data. The steadystate gas data together with wind data are presented in the fourth section, which also discusses calculation of $\mathrm{K}^{\mathbf{r}}$ by eq. 22 . The last section evaluates the increase of gas desorption due to wind by use of eq. 25. 


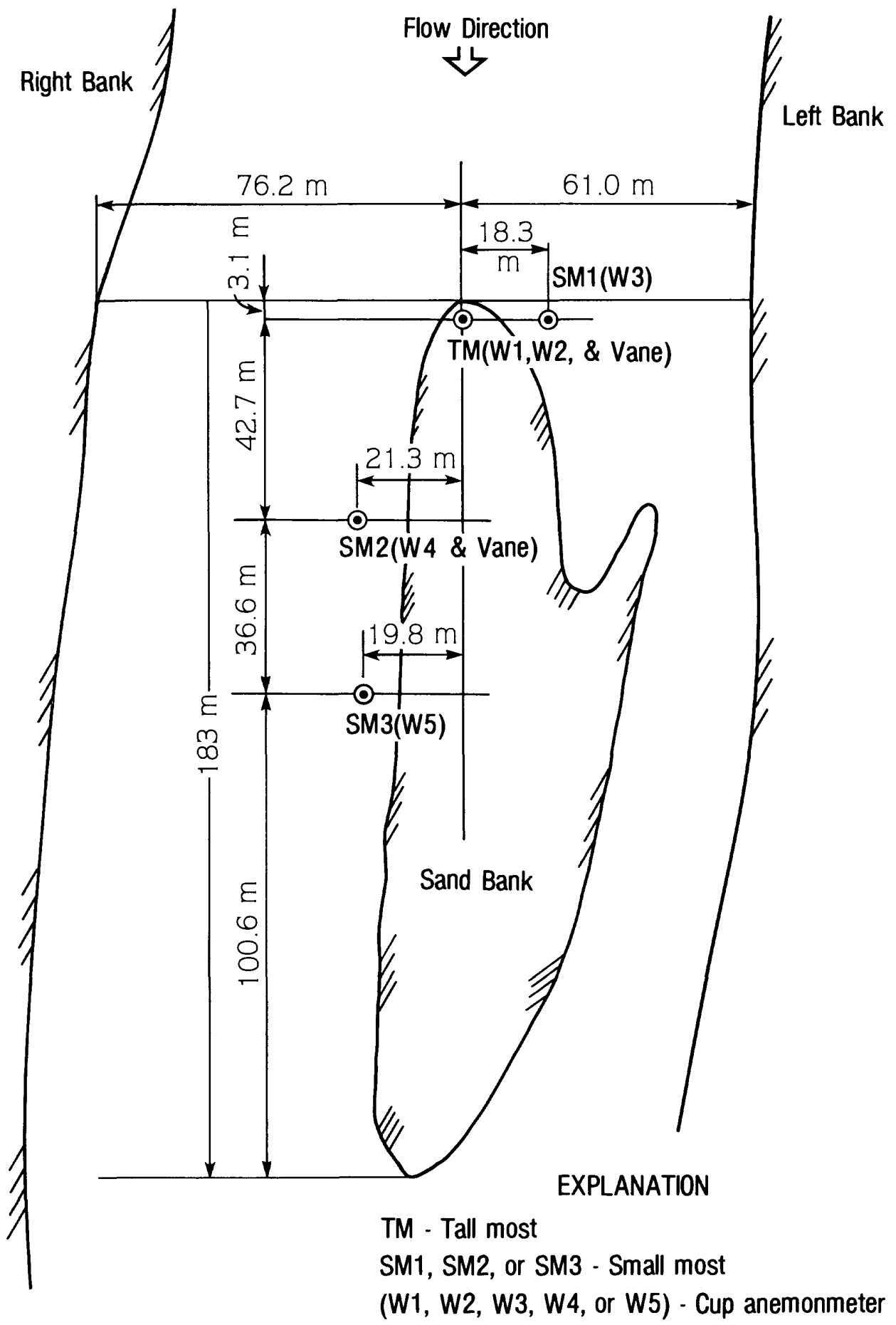

Fig. 2.--Sketch of the wind measurement station. 
The mean travel time, $\bar{t}$, and several moments involved in the correction term, E, both of which are needed for eq. 22, are calculated from the dye cloud data observed along three streamlines at the two cross sections resulting from the instantaneous injection on Aug. 5, 1982. Figures 3 and 4 present the temporal variation of dye concentration at the upstream and downstream section, respectively. All dye concentrations were determined by the standard fluorometric analysis (Hubbard and others, 1982) at the New York Subdistrict Laboratory of U.S. Geological Survey. The average background concentration of $0.05 \mu \mathrm{L}^{-1}$ was uniformly subtracted from all dye concentrations determined by the fluorometer. The tail of a dye cloud less than 2 percent of the peak concentration was extrapolated by assuming a linear relation between the logarithm of concentration with time. The tail extrapolations at the 10 and 30 percent streamlines of the downstream section may not have been very satisfactory, because the last dye concentrations obtained at the two locations were much higher than 2 percent of the peak value. For all dye clouds, $t_{D}(x, q)$ was fixed at the time when the dye concentration was at 2 percent of the peak value as recommended in the first report.

The calculation from dye cloud data are based on eqs. 4, 11, and 16, which were expressed in terms of the normalized response function of a hypothetical conservative tracer. The mean travel time $\bar{t}(x, q)$, and correction term, $E(x, q)$, may be rewritten as

$$
\bar{t}(x, q)=\frac{\int_{0}^{\infty} c_{c}(x, q, t) d t}{\int_{0}^{\infty} c_{c}(x, q, t) d t}
$$




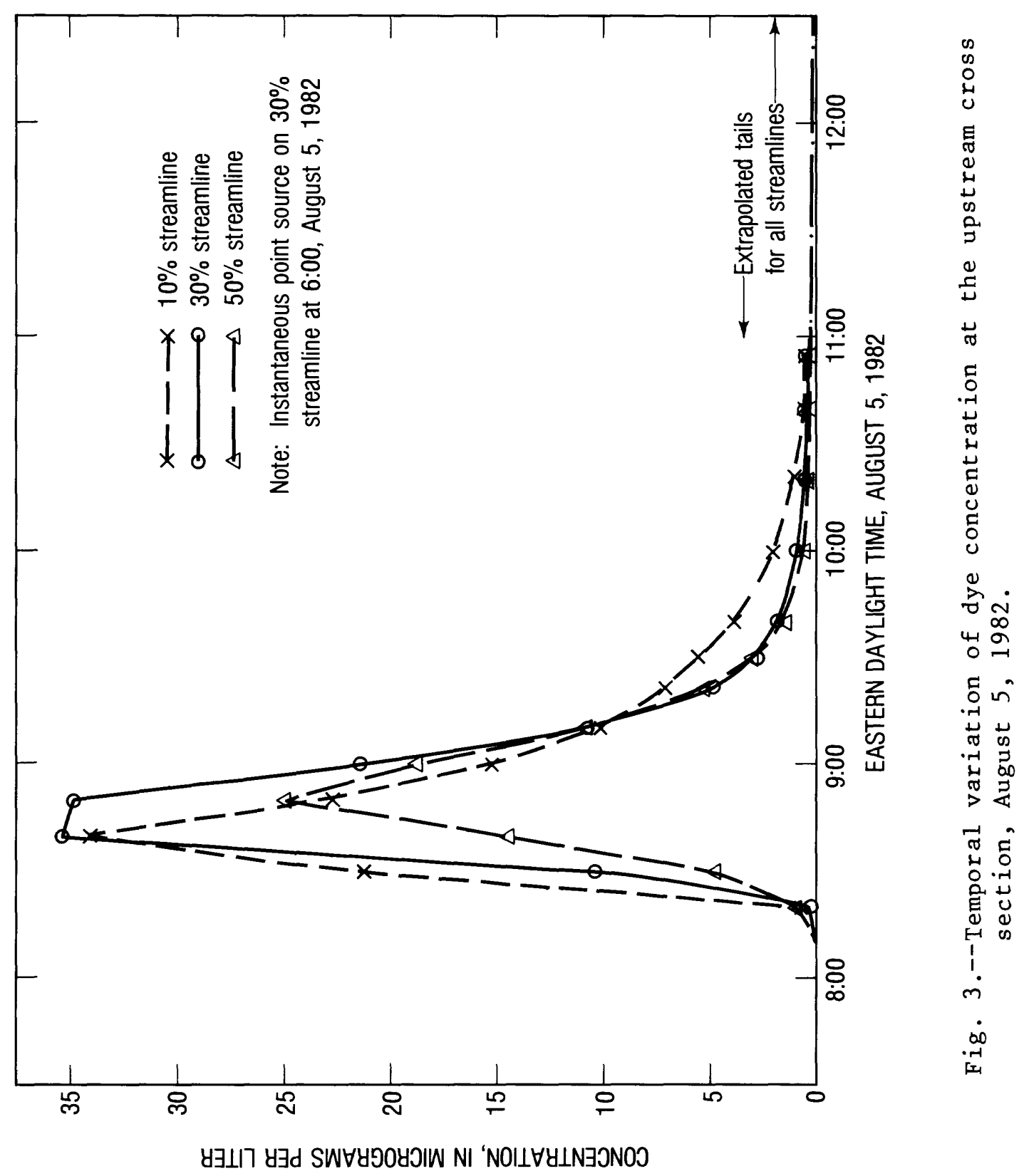




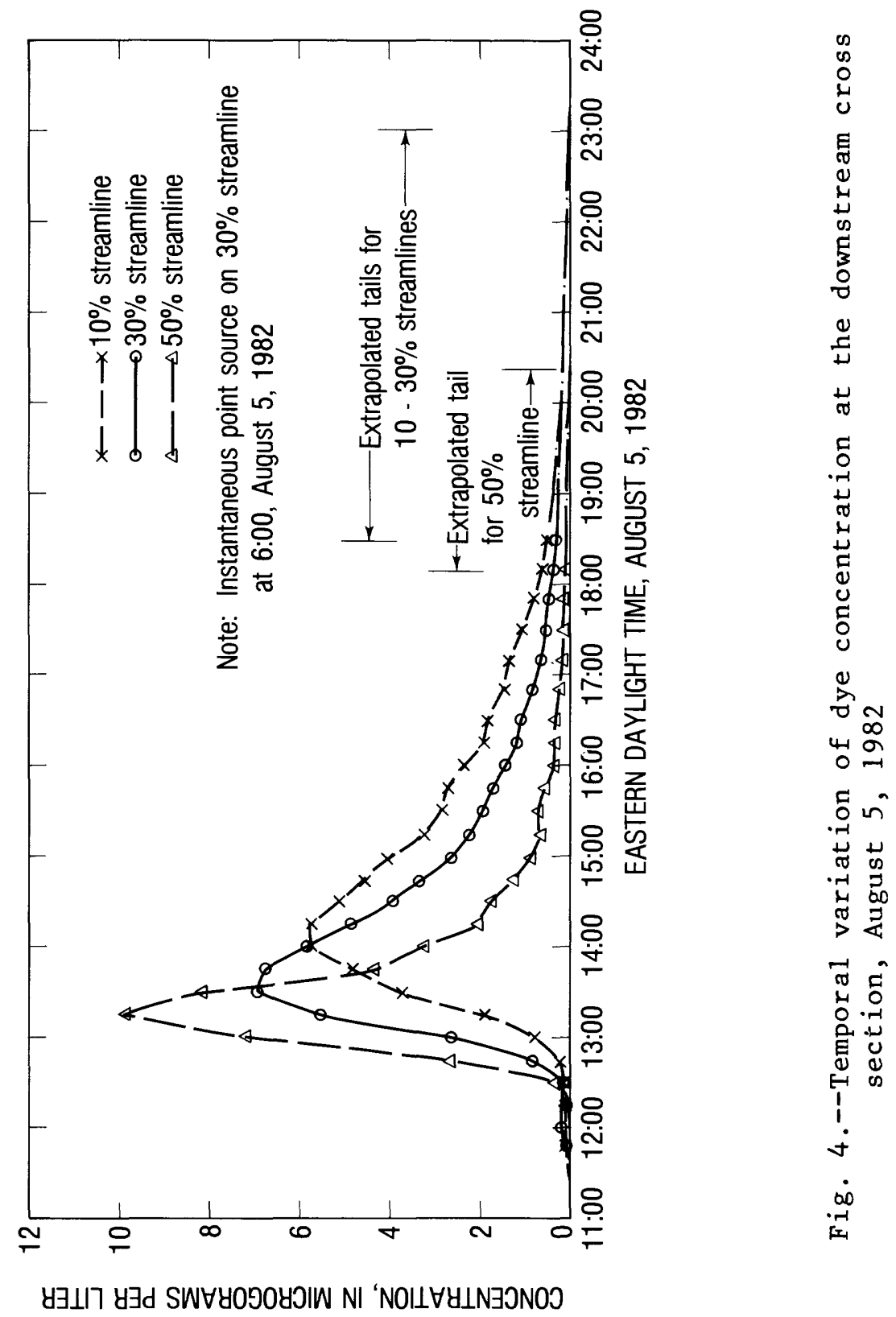




$$
E(x, q)=1+\sum_{n=2}^{\infty} \frac{(-1)^{n} k^{n}}{n !} \frac{\int_{0}^{\infty}[t-\bar{t}(x, q)]^{n} c_{c}(x, q, t) d t}{\int c_{c}(x, q, t) d t}
$$

If the assumption is made as in the first report that the fractional dye loss is small and constant during the passage of dye cloud, $C_{c}(x, q, t)$ of eqs. 26 and 27 may be replaced with the concentration, $C_{r}(x, q, t)$, with dye loss terms being eliminated between numerators and denominators. Furthermore, for a typical form of $C_{c}(x, q, t)$ and a typical value of propane desorption coefficient, $K$, the terms of eq. 27 involving the moments higher than third-order may be considered negligible.

Eqs. 26 and 27 are now replaced by the following set of equations for dye concentration

$$
\begin{aligned}
& a(x, q)=\int_{0}^{\infty} C_{r}(x, q, t) d t \\
& \bar{t}(x, q)=\frac{1}{a} \int_{0}^{\infty} t C_{r}(x, q, t) d t \\
& s^{2}(x, q)=\frac{1}{a} \int_{0}^{\infty}[t-\bar{t}(x, q)]^{2} C_{r}(x, q, t) d t \\
& s^{3}(x, q)=\frac{1}{a} \int_{0}^{\infty}[t-\bar{t}(x, q)]^{3} C_{r}(x, q, t) d t \\
& E(x, q)=1+\frac{K^{2}}{2} s^{2}(x, q)-\frac{K^{3}}{6} s^{3}(x, q)
\end{aligned}
$$

Eqs. 28 and 29 are the zeroth and first order moments about $t=0$ of the dye cloud, respectively. Eqs. 30 and 31 are the second and third order moments about the mean time, $\bar{t}$, of the dye cloud, respectively.

Four moments were calculated from dye cloud data of figures 3 and 4, using a discrete integration scheme of eqs. 28-31. The results are tabulated in table 1. The integration scheme assumes a linear variation of concentration between $C_{r}\left(t_{i}\right)$ and $C_{r}\left(t_{i+1}\right)$, where $i$ is the integer index of the time of 


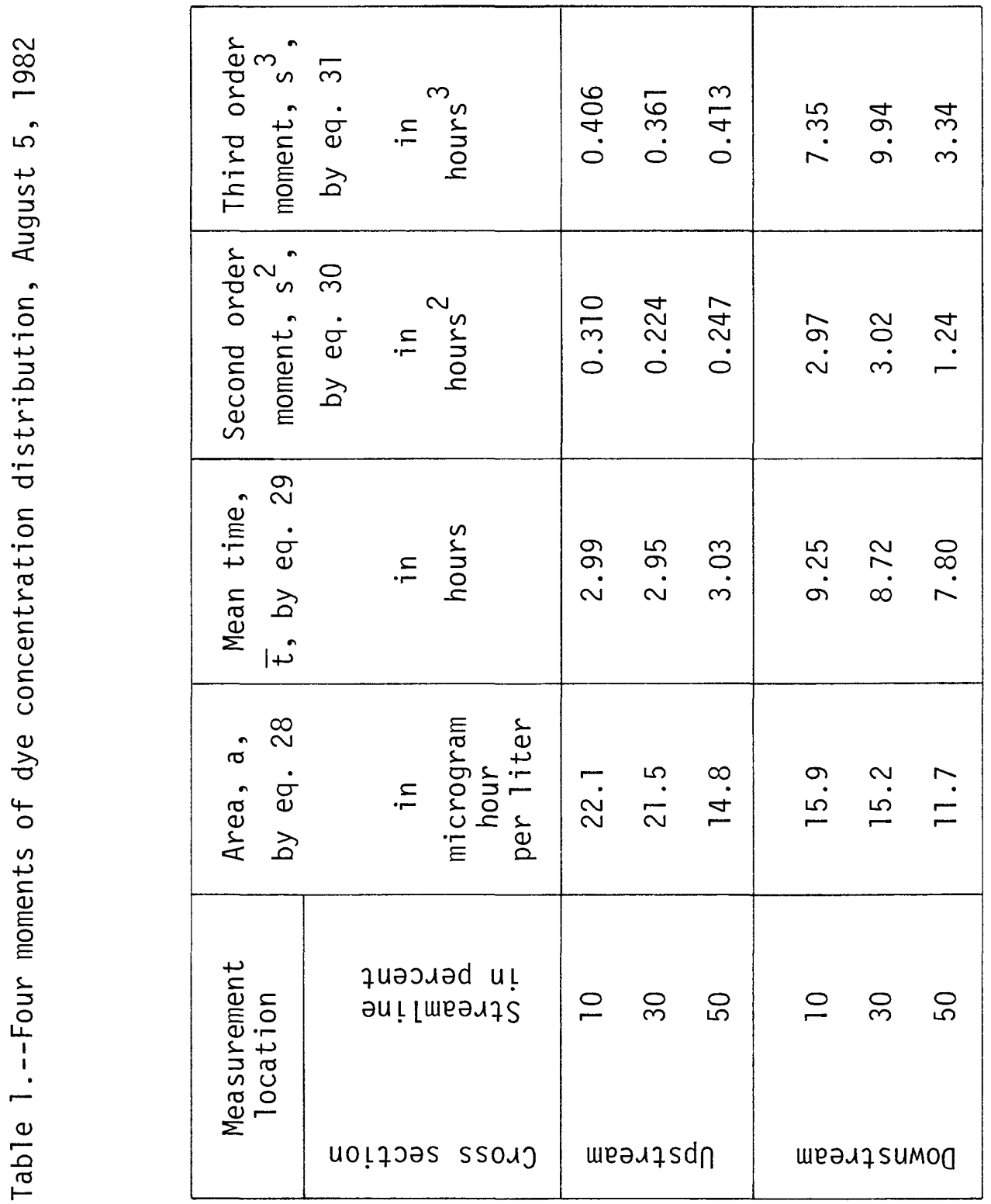


dye sampling, and calculates various moments by use of analytical forms available for a trapezoid. This scheme provides more accurate calculation of moments than the scheme used in the first report, which assumes that $C_{I}\left(t_{i}\right)$ is constant between the times $\frac{1}{2}\left(t_{i-1}+t_{i}\right)$ and $\frac{1}{2}\left(t_{i}+t_{i+1}\right)$ (E.R. Holley, 1983, University of Texas, written commun.). A comparison of the two schemes showed that the error is less than 0.3 percent for a and $\bar{t}$, about 5 to 7 percent for $s^{2}$, and 12 to 18 percent for $s^{3}$. However, for a moderate value of $k$ these large errors in $s^{2}$ and $s^{3}$ have negligible effects on the value of $E$ so that the integration scheme used in the first report may still be used for many practical purposes. For this reason, the detailed description of the present integration scheme will be omitted here.

\section{Mass Distribution Factor, $\phi$}

The mass distribution factor, $\phi$, of eq. 22 was to be calculated from the steady-state dye plume data resulting from the 9-hour continuous injection, Aug. 4, 1982. The justification for this comes from eq. 15. Considering a conservative tracer, for which $\mathrm{K}=0$ and $\mathrm{E}=1$, eq. 15 may be written as

$$
\phi(x, q)=\frac{Q(x) C_{c}(x, q)}{\int_{0}^{Q} C_{c}(x, q) d q}
$$

where $C_{c}(x, q)$ is the steady-state concentration of conservative tracer and the injection rate, $m_{c}$, of eq. 15 is replaced by $\int_{0}^{Q} C_{c}(x, q) d q$ because $\int_{0}^{Q} \phi(x, q) d q=Q$ by definition. As in the case of dye cloud data discussed previously, $C_{c}(x, q)$ of eq. 33 may be replaced by the steady-state dye concentration $C_{r}(x, q)$ without involving dye losses. 
When the dye plume samples were analyzed at the U.S. Geological Survey Laboratory in Albany, New York, however, it was discovered that the steady-state concentration was not obtained at all throughout the measurement period of Aug. 4, 1982. Apparently there was a basic failure in the dye injection mechanism. It was thus necessary to abandon the use of eq. 33 and to handle the dye data as prolonged but transient dye clouds. At the upstream cross section, enough dye samples were available to plot the temporal variation of $C_{r}(x, q, t)$ at five streamlines with $r=$ $10,30,50,70$, and 90 percent. For other streamlines with $\mathrm{r}=20,40$, 60 , and 80 percent, the rising and declining sides of dye cloud were interpolated from the data at two neighboring streamlines. Dye cloud data at the upstream cross section are presented in figure 5. At the downstream cross section, where the dye sample collection had to be terminated at 9:00 pm, Aug.4, 1982, there was no way to plot the temporal variation of $C_{r}(x, q, t)$ in its entirety. The partial dye concentration data at the downstream cross section are presented in figure 6 .

It appears from figure 5 that the two interruptions of dye injection at 10:50 am and 2:00 pm, Aug.4, that were observed by the injection crew, correspond to major troughs in dye concentration at the upstream section at about 1:40 pm and 4:40 pm. Because the travel time between the injection site and the upstream section was 3 hours, major interruptions in the injection must have occurred at about 10:40 am and 1:40 pm. It also appears that the interruptions were much longer than the crew's assumption in the field and were indicative of a failure in the injection mechanism. One interesting aspect of figure 5, however, is that the dye concentration at all streamlines began a sharp decline at about 7:40 pm. This time was 9 hours after the arrival of dye at the upstream section at about 10:40 am. Remembering that the duration of dye injection was 


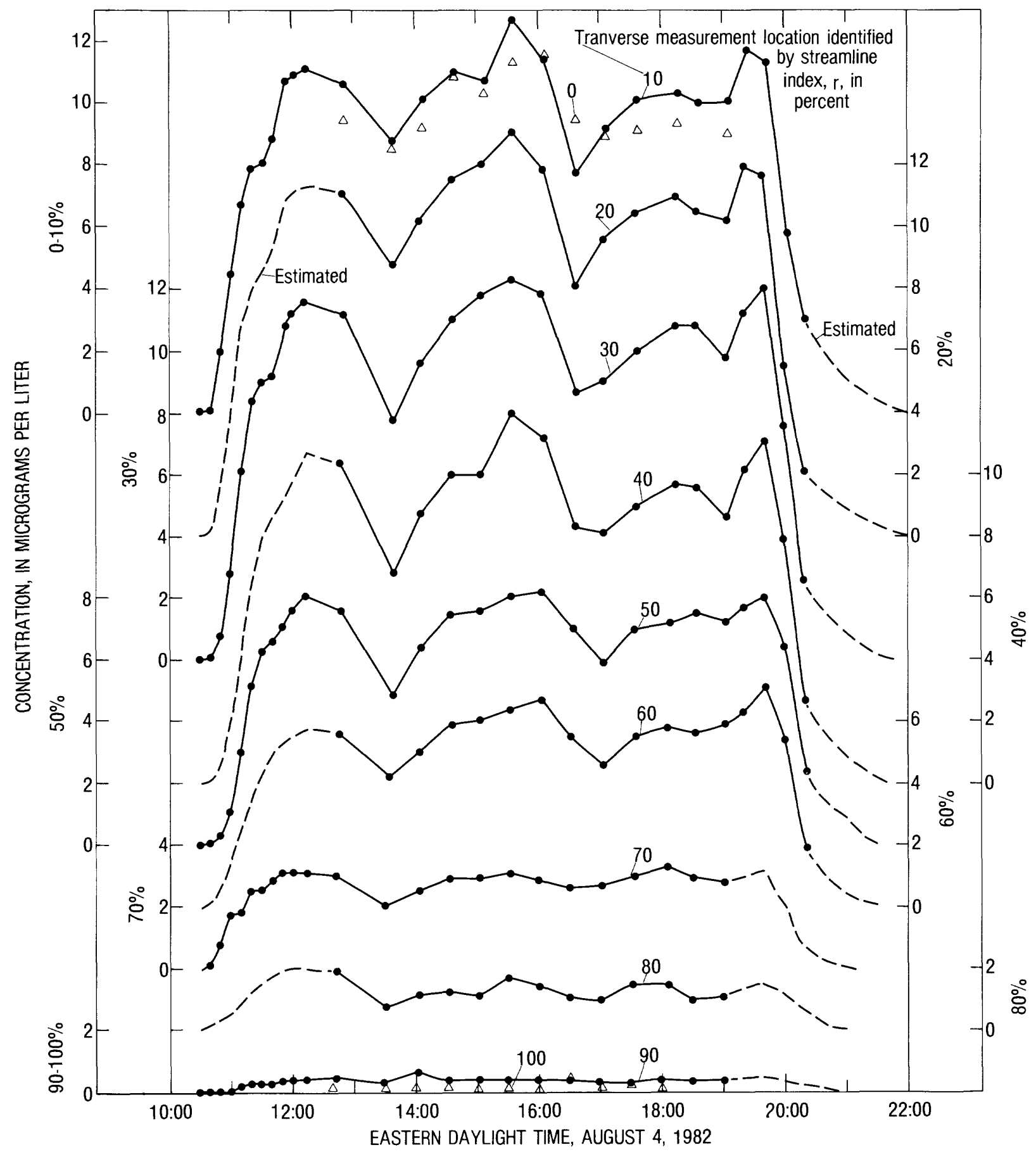

Fig. 5.--Temporal variation of dye concentration at the upstream cross section, August 4, 1982 . 


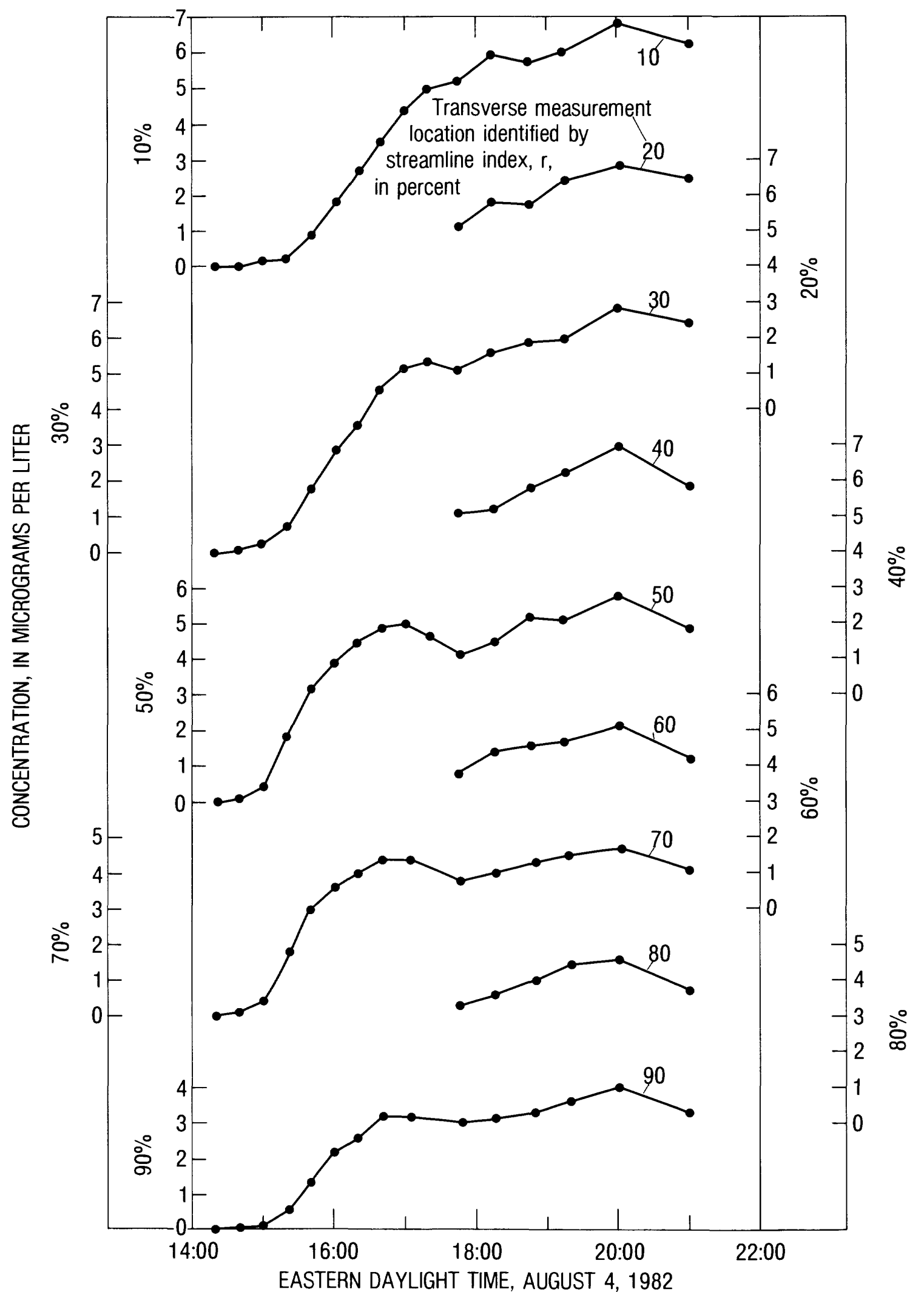

Fig. 6.--Temporal variation of dye concentration at the downstream cross section, August 4, 1982 . 
precisely 9 hours, the above behavior of dye data is a demonstration of validity of the superposition principle, which was explained in detail in the first report and repeated briefly following eq. 9 of this report.

The justification for calculating $\phi$ from the unsteady data of figure 5 may be obtained by referring to eq. 8. For a conservative tracer with a time-dependent injection rate, $m_{c}(\tau)$, eq. 8 may be modified as

$$
C_{c}(x, q, t)=\frac{\phi(x, q)}{Q(x)} \int_{0}^{\tau} I m_{c}(\tau) f(x, q, t-\tau) d \tau
$$

Integrating both side of eq. 34 with respect to $t$ from zero to infinity and rearranging,

$$
\phi(x, q)=\frac{Q(x) \int_{0}^{\infty} C_{c}(x, q, t) d t}{\int_{0}^{\infty} \int_{0}^{\tau_{I}} m_{c}(\tau) f(x, q, t-\tau) d \tau d t}
$$

The double integral of eq. 35 can be shown to be equal to the total injected mass, $\int_{0}^{\tau} I m_{c}(\tau) d \tau=M_{c}$, by switching the order of integration and noting that $\int_{0}^{\infty} f(x, q, t-\tau) d t=1$. Therefore, eq. 35 becomes identical to eq. 5 , in which $C_{c}(x, q, t)$ now represents the concentration of conservative tracer whether the injection is instantaneous or continuous. Again introducing the assumption of constant loss for dye, eq. 5 may be written for dye as

$$
\phi(x, q)=\frac{Q(x) \int_{0}^{\infty} C_{r}(x, q, t) d t}{\int_{0}^{Q} \int_{0}^{\infty} C_{r}(x, q, t) d t d q}
$$

The areas under the concentration-time curve of figure 5 were carefully measured for nine streamlines, $r=10,20, \ldots, 90$ percent. For the left bank where $r=0$, the concentration was assumed the same as at $r=10$ 
percent, while at the right bank, $r=100$, the concentration was steady at $0.1 \mu \mathrm{L} \mathrm{L}^{-1}$ and the two ends of the curve were estimated from the data at $r=90$ percent. The measured areas were then multiplied by appropriate subdischarge, $\Delta q / Q$, and summed for the entire cross section to provide the denominator of eq. 36. The calculation of $\phi$ for the upstream section is presented in table 2. Note that only $\phi_{u}^{10}=1.64, \phi_{u}^{30}=1.64$, and $\phi_{u}^{50}=1.13$ are needed for the calculation of $k^{\Gamma}$. These values were checked indirectly by the dye cloud data of Aug. 5, 1982, as follows. Noting that the area, a, listed in the first column of table 1 represents $\int_{0}^{\infty} C_{r}(x, q, t) d t$ of eq. 36, the ratios, $a_{u}^{10} / a_{u}^{50}$ and $a_{u}^{30} / a_{u}^{50}$, obtained from the dye cloud data, Aug. 5, should be the same as the ratios, $\phi_{u}^{10} / \phi_{u}^{50}$ and $\phi_{u}^{30} / \phi_{u}^{50}$, calculated above from the dye data, Aug. 4. The former ratios are 1.49 and 1.45 and the latter ratios are 1.45 and 1.45 , respectively, and the difference at the 10 percent streamline is about 3 percent.

A similar calculation was impossible for the downstream cross section, where the dye data were incomplete as shown in figure 6 . It was also obvious that dye concentrations at the 10 and 30 percent streamlines in figure 6 were not at steady-state even at 9:00 pm, Aug. 4. For the downstream cross section, therefore, the only usable dye data were provided by the injection on Aug. 5, 1982--namely, the area, a, in the first column of table 1. However, these areas are proportional to but not directly reducible to numerical values of $\phi$. In order to overcome this difficulty and to help estimate $\phi_{\mathrm{d}}^{50}$ in particular, use was made of the stream-tube model of Yotsukura and Cobb (1972). The approach was to simulate the distribution of $\phi$ observed at the upstream cross section and then, utilizing the same parameters, to estimate a distribution at the downstream section. 


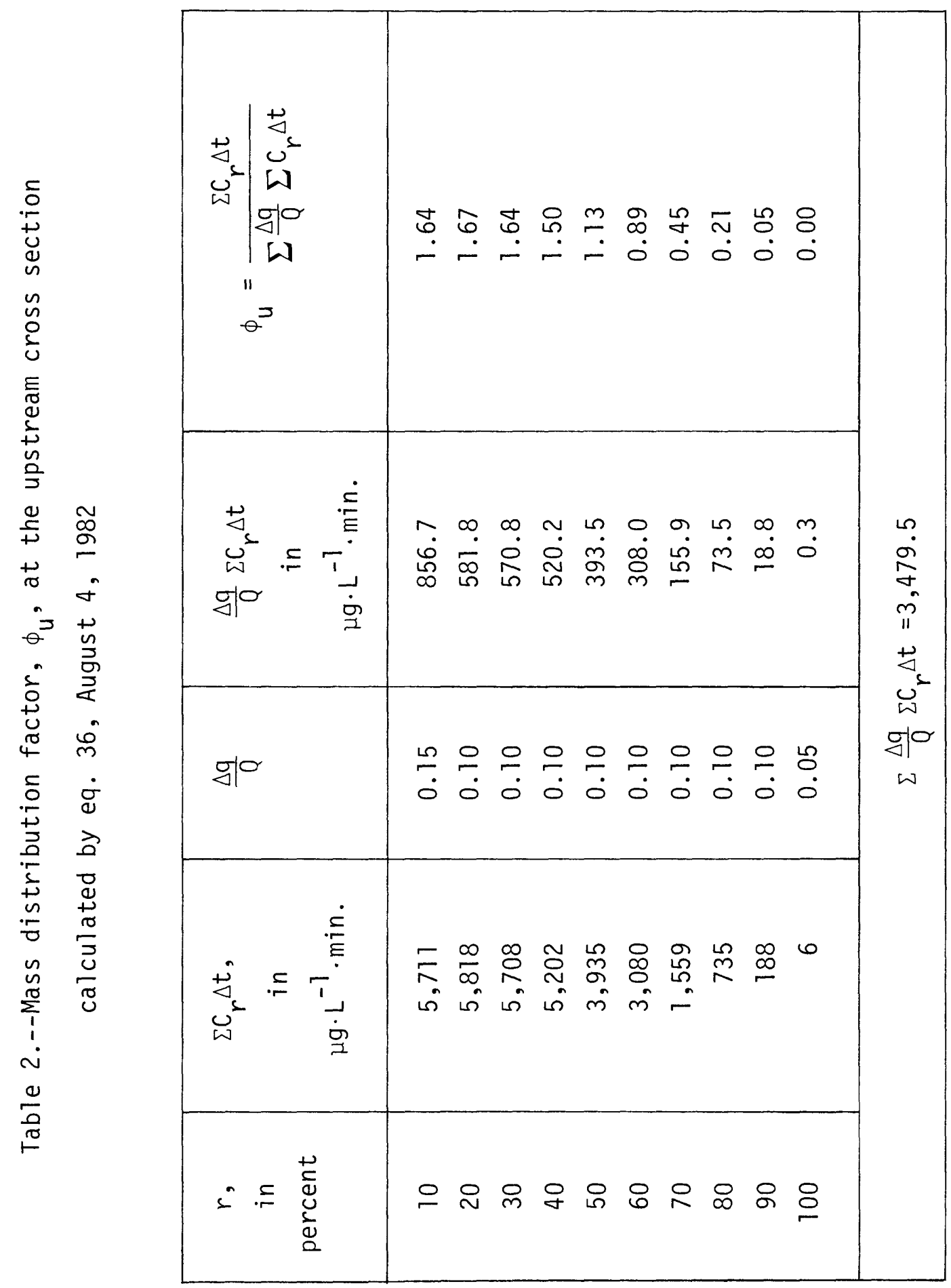


The two-dimensional steady-state concentration given by the streamtube model may be written as

$$
\phi(\xi, n)=\frac{1}{\sqrt{4 \pi \xi}} \sum_{N=-\infty}^{\infty}\left[\exp \left\{\frac{-\left(2 N+n_{s}+n\right)^{2}}{4 \xi}\right\}+\exp \left\{\frac{-\left(2 N+n_{s}-n\right)^{2}}{4 \xi}\right\}\right]
$$

where

$$
\xi=\frac{x D_{2}}{U W^{2}}, \eta=\frac{q}{Q} \text {, and } \eta_{s}=\frac{q_{s}}{Q}
$$

The notations $\xi$ and $\eta$ are the nondimensional longitudinal and transverse coordinates and $D_{z}$ designates the transverse mixing coefficient. The point source location is designated by $\eta_{s}$, which is equal to 0.3 in the present test. A computationally adequate range of the integer index $N$ is from -4 to +4 .

Figure 7 presents a comparison of the observed and simulated $\phi_{u}^{r}$ distributions. The simulation with $\xi_{u}=0.035$ appears to be the best if the emphasis is given to the left half of the channel, where the concentration is high and the measurement error is supposedly small. The value of the transverse mixing coefficient, $D_{z}$, could be estimated from the discharge measurement of Aug.3, and dye data of Aug. 5, 1982. The discharge $Q$ was $14.7 \mathrm{~m}^{3} \mathrm{sec}^{-1}$, the average travel time, $\bar{t}$, was 2.99 hours for the distance, $x_{u}$, of $3.22 \mathrm{~km}$. Thus the average velocity $U$ between the injection site and the upstream section was $0.30 \mathrm{~m} \mathrm{sec}^{-1}$. The reachaveraged channel width, $W$, was $91 \mathrm{~m}$ and the slope, $\mathrm{S}$, was 0.000847 . The first equation in eq. 38 gives $D_{z}$ as $0.027 \mathrm{~m}^{2} \mathrm{sec}^{-1}$ for $x_{u}=3.22 \mathrm{~km}$ and $\xi_{u}=0.035$. A commonly used form for $D_{z}$ is

$$
\mathrm{D}_{2}=\alpha \mathrm{H} \mathrm{U}_{*}
$$

where $U_{*}$ is the shear velocity and $\alpha$ is a nondimensional constant. Because the reach-averaged depth $\mathrm{H}=\mathrm{Q} /(\mathrm{UW})$, was $0.54 \mathrm{~m}$ and $U_{*}$ was $0.067 \mathrm{~m} \mathrm{sec}{ }^{-1}$, the value of $\alpha$ was 0.75 , a very reasonable value for the configuration 


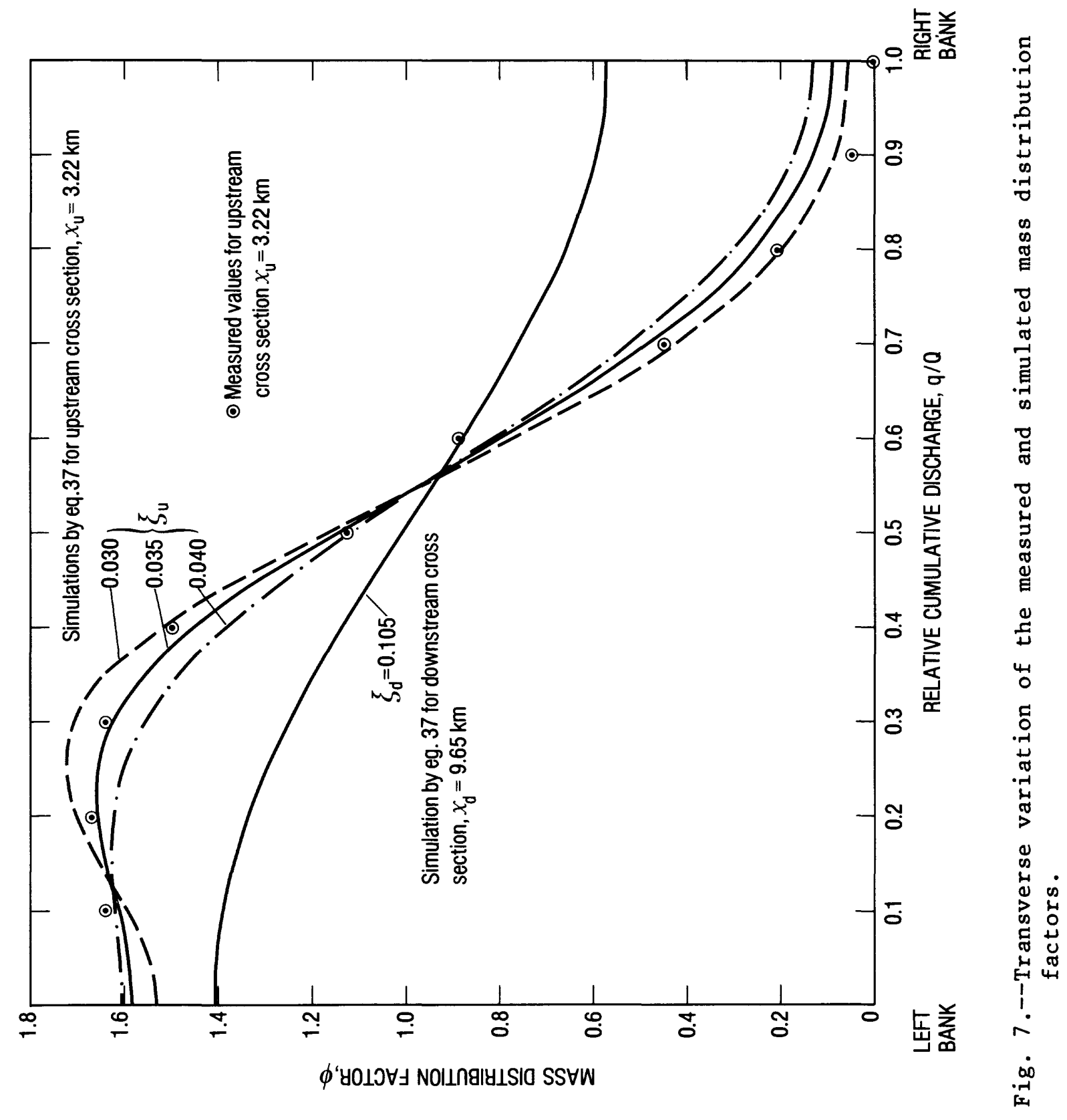


and alignment of the reach shown in figure 1 (Fischer and others, 1979). Assuming that $D_{2}, U$, and $W$ remain constant, the nondimensional distance to the downstream section, $\xi_{d}$, was 0.105 , because $x_{d}=3 x_{u}$. When $\phi_{d}^{50}$ was simulated from eq. 37 , however, it was discovered to be very close to unity--namely $\phi_{d}^{50}=1.02$ for $\xi_{d}=0.085$, and $\phi_{d}^{50}=1.00$ for $\xi_{\mathrm{d}} \geq 0.125$. A simulated curve for $\phi_{\mathrm{d}}$ with $\xi_{\mathrm{d}}=0.105$ is shown in figure 7 . After examining several simulations for a range of $\xi_{\mathrm{d}}$ between 0.085 and 0.125 , it was decided that the best estimate of $\phi_{d}^{50}$ was unity for all practical purposes. The values of $\phi_{\mathrm{d}}^{10}$ and $\phi_{\mathrm{d}}^{30}$ were then estimated from the ratio of the areas, a, listed in table 1 . The final mass distribution factors at the downstream section were $\phi_{d}^{10}=1.36, \phi_{d}^{30}=1.30$, and $\phi_{d}^{50}=$ 1.00. Note that these $\phi_{\mathrm{d}}^{10}$ and $\phi_{\mathrm{d}}^{30}$ values determined from dye data of Aug. 5 are -2 and +4 percent off the simulated values shown in figure 7 .

\section{Wind Speed, $\mathrm{U}_{\mathrm{a}}$}

The wind speed variation at the five measurement points, together with wind direction and other meteorological parameters, are summarized in table 3. Paying particular attention to wind measurements, W3, W4, and W5, which represent conditions directly above the water surface, the entire period may be divided into two subperiods. The first period of reasonably high speed ( $\geq 1 \mathrm{~m} \mathrm{sec}^{-1}$ ) was from 8:00 am to 10:00 pm, August 4, with winds flowing from the south against the direction of the river flow. The second period of low wind speed $\left(\leq 1 \mathrm{~m} \mathrm{sec}^{-1}\right)$ was from 10:00 pm, August 4, to 8:00 am, August 5, during which the wind shifted to a direction from the south but was quite variable. The wind directions measured by two 


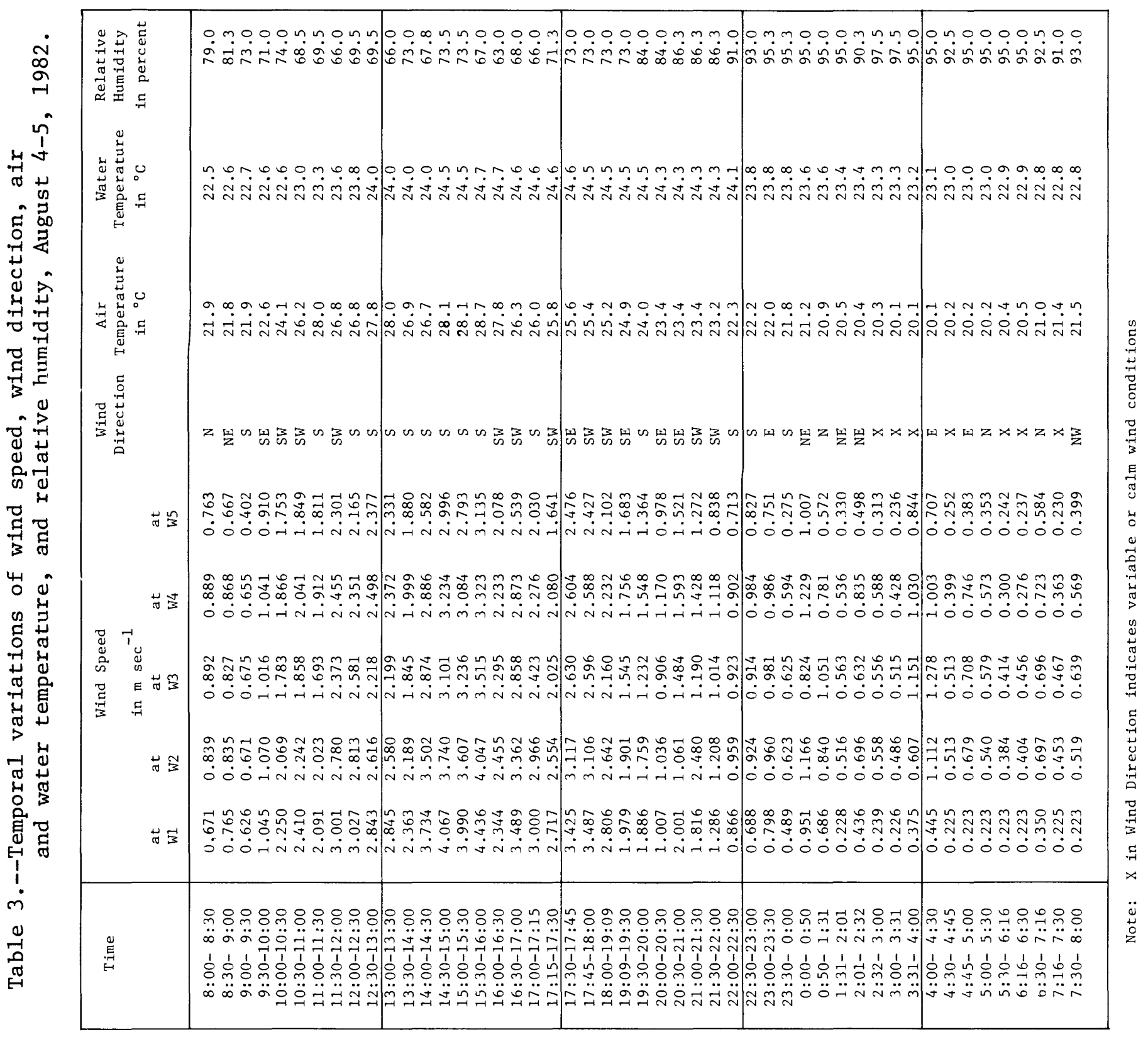


vanes on TM and SM2 masts were practically identical, so that only one reading is included in table 3 . Because the three near-surface anemometers showed relatively minor variability, their arithmetic average was considered as the average wind speed and was used in the analysis.

\section{Propane Desorption Coefficients, $\mathrm{K}^{\mathrm{T}}$}

Figures 8 and 9 present time series data of propane gas concentrations at the upstream and downstream measurement locations, respectively. All gas samples were shipped to the U.S. Geological Survey Central Laboratory, in Atlanta, Georgia, for standard gas chromatographic analysis. Immediately before the analysis, however, a substantial number of the gas samples were found to have developed air bubbles at the vial top, which did not exist at the time of shipping. The most probable cause of this problem was that the vial caps, which were tightened only at the time of sampling, became loose in the process of handling and shipping. In figures 8 and 9 , the solid points indicate gas samples without air bubbles and the open points indicate samples with tolerable air bubbles. Another problem was the loss of data in figure 9 between $8: 00$ am and 12:00 pm, Aug. 5. The sampling crew inadvertently placed the wrong side of the septum in contact with the sample water, and caused substantial adsorption of gas onto the septum. More than 30 percent of the original gas concentration was absorbed to the surface of the septum not coated by Teflon.

Figures 8 and 9 show only gas data that were at steady-state in the sense of satisfying the requirement for tracer mixing explained previously. The period of steady-state and the mean residence time as determined from dye cloud data are tabulated in table 4. Even though additional gas samples were collected, in particular, at the downstream sections, these are 


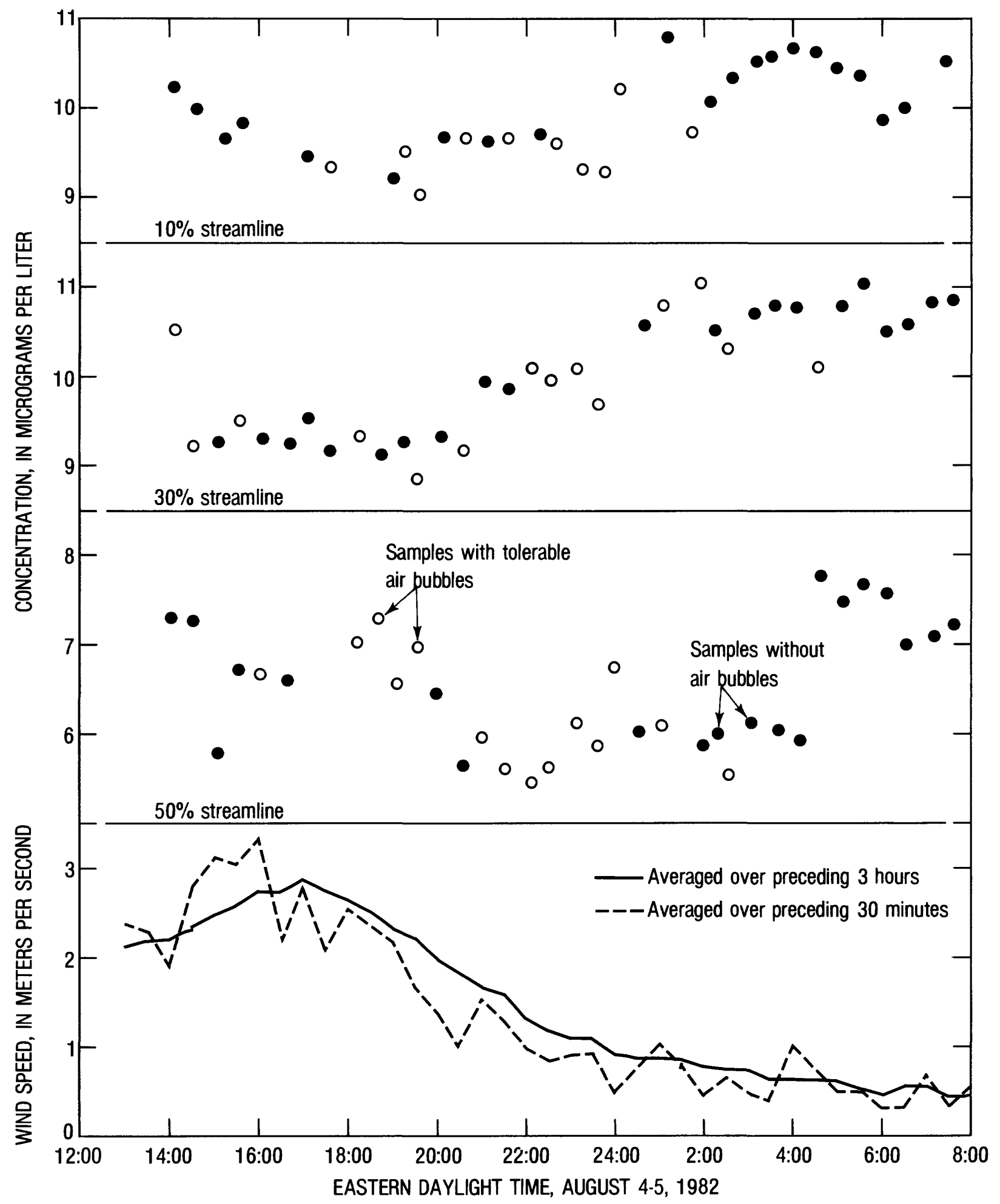

Fig. 8.--Temporal variations of gas concentration and wind speed at the upstream cross section, August 4-5, 1982 . 


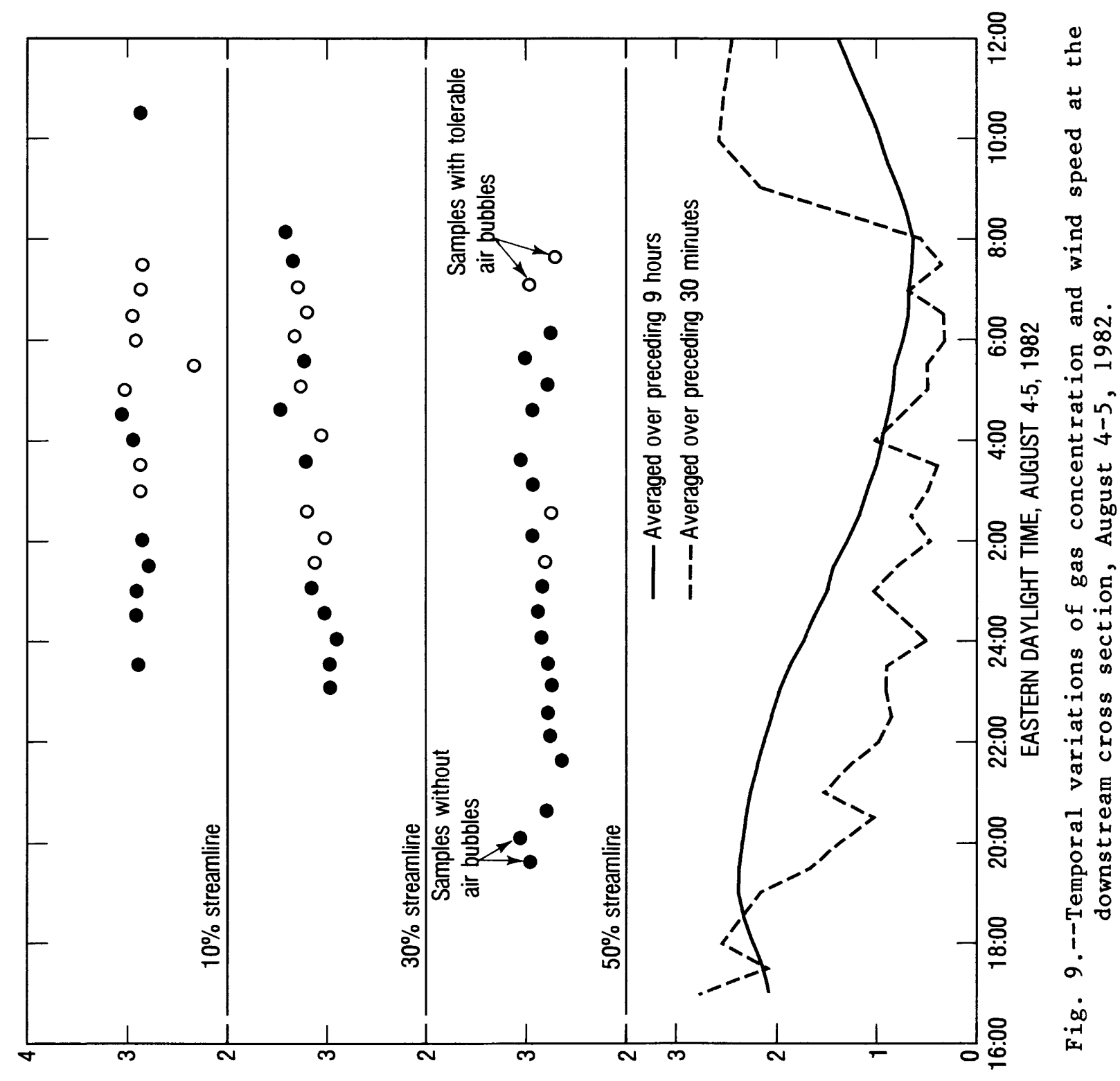

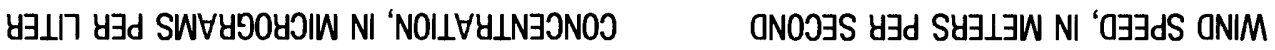




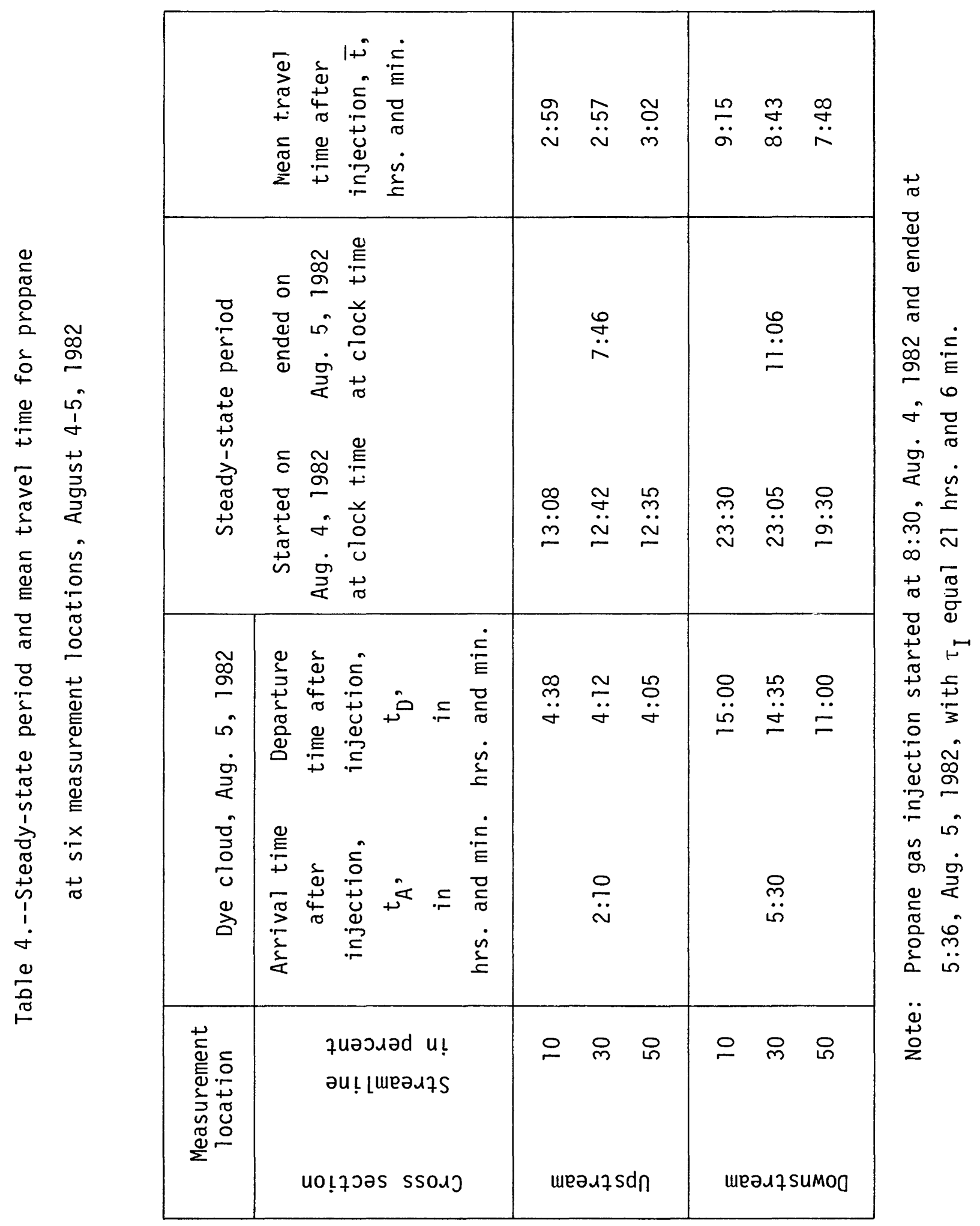


omitted for clarity in figures 8 and 9 because they were collected outside the steady-state period.

All gas data have temporal variations, which appear to be due to wind effects directly and indirectly. The data for $\mathrm{C}_{u}^{30}$ have the clearest trend with time, whereas $\mathrm{C}_{\mathrm{u}}^{50}$ has some inexplicable variations between 5:00 pm and 10:00 pm, Aug.4, and then again between 4:00 am and 4:30 am, Aug. 5 . In addition, at the upstream section, gas concentrations at all streamlines decline between 6:00 am and 7:00 am, Aug. 5. This decline appears to indicate that the gas inflow rate at about the time of switching of the supply tanks--3:00 am and 3:45 am, Aug. 5, was reduced substantially from the steady rate of $30 \mathrm{~L} \mathrm{min.}^{-1}$ At the downstream locations, all concentrations are less variable with time and the steady pattern of $c_{d}^{50}$ is quite remarkable in comparison with $\mathrm{c}_{\mathrm{u}}^{50}$. The concentrations, $\mathrm{C}_{\mathrm{u}}^{30}$ and $\mathrm{C}_{\mathrm{d}}^{30}$, which are on the tracer source streamline, have the most consistent trend.

At the bottom of figures 8 and 9 , time series of wind data are presented for comparison with the gas data. The averaged wind speed, $\bar{U}_{a}\left(t_{s}\right)$, is based on $\Delta t=3$ hours for figure 8 , and 9 hours for figure 9 . These averaging periods are approximately equal to the mean travel time, $\bar{t}$, from the injection location to the respective cross sections. Note that the time coordinate is adjusted such that $\bar{U}_{a}$ at the time of gas sampling, $t_{s}$, indicates the averaged wind speed between $t_{s}-\bar{t}$ and $t_{s}$, to which the average tracer particle has been exposed in its travel downstream. In addition, the original wind speed data, which are based on $\Delta t=1 / 2$ hour, are superimposed to illustrate the approximate variability of instantaneous wind speed $U_{a}(t)$. Note that, except for $C_{u}^{50}$, the times of high and low wind speed $\bar{U}_{a}$, agree well with the times of low and high gas 
concentration and, again, this trend is the clearest for $\mathrm{C}_{\mathrm{u}}^{30}$ and $\mathrm{c}_{\mathrm{d}}^{30}$.

The strange behavior of $\mathrm{C}_{\mathrm{u}}^{50}$ between $5: 00 \mathrm{pm}$ and 10:00 pm, Aug. 4, could be due to possible lateral movements of the tracer plume under the effect of high wind speed during this period. The concentration $c_{u}^{50}$ was measured at the location where, according to figure 7 , the transverse gradient of tracer concentration as indicated by $\Delta \phi / \Delta \eta$ was highest at about 3.25 , indicating that an intense transverse mixing was occurring at this location. As for the sudden jump of $\mathrm{C}_{\mathrm{u}}^{50}$ between 4:00 and 4:30 am, or relatively speaking, its drop between 2:30 and 4:00 am, Aug. 5, the chance of lateral plume movement is lower because the wind speed was at the lowest level in this period even though some events of crosswinds occurred as shown in table 3 .

In comparing $C_{u}^{50}$ data with all other $C^{\prime} s$, the reliability of a single value for $\phi_{u}^{50}$ determined by dye data may be questioned. Despite the previous assumption of time invariance of $\phi$ with respect to $q$, actual measurements of $\phi$ were done at fixed locations, treating $\phi$ as a function of $z$. Thus, the measured values of $\phi_{u}^{50}$ could have been time dependent under variable wind shear because the transverse gradient of $\phi_{u}^{50}$ was high. At other measurement locations, however, the transverse gradient of $\phi$ was low and the possible error for $\phi$ was small even under lateral wind shear. Because of the failure of the steady-state dye test, which could have resolved this problem, the data for $\mathrm{C}_{\mathrm{u}}^{50}$ were judged to be useful only if all values were averaged to a single value, which could be used together with $\phi_{u}^{50}=1.13$.

A conclusion in the first report was that the random variation of steady-state gas concentration was within \pm 5 percent of the mean in the windless tracer test of Cowaselon Creek, Oct., 1981. The data in figure 8 
and 9 appear to have a simflar random variation, despite the expectation that the error in a 2-dimensional plume would be somewhat higher than in a 1-dimensional plume. An unfortunate situation in the use of eq. 22 was that the steady-state gas data at the downstream section were limited to 5 hours for $C_{d}^{10}$ and 9.5 hours for $c_{d}^{30}$. Thus, the corresponding upstream gas data were restricted to the similar time period and some good upstream concentration data could not be used for the calculation.

Tables 5 and 6 present the calculation of $\mathrm{K}^{10}$ and $\mathrm{k}^{30}$, respectively. In most calculations, a pair of single concentrations at upstream and downstream, marked by solid points in figures 8 and 9 , were utilized. Following eq. 22, these two concentrations were separated by the mean travel time between the two cross sections. As explained previously, the first $K^{r}$ was calculated by assuming $E=1$, and the second and final $\mathrm{K}^{\mathrm{r}}$ was calculated by including the correction factor, $\mathrm{E}$, which was calculated by means of eq. 32 with the dye moment data tabulated in table 1 and the first $\mathrm{K}^{\mathrm{r}}$ value. For the magnitude of desorption coefficient shown in tables 5 and 6 , it appears that the $E$ term is mostly controlled by the second moment, $s^{2}$, and is less than 1.04 .

As for gas data along the 50 percent streamline, only one calculation from eq. 22 was made by utilizing $C_{u}^{50}=6.22 \mu \mathrm{L} \mathrm{L}^{-1}$ and $C_{d}^{50}=2.89 \mu \mathrm{g} \mathrm{\textrm {L } ^ { - 1 }}$ The $\mathrm{K}^{50}$ was found to be $0.137 \mathrm{hr}^{-1}$ with other parameters being, $\phi_{\mathrm{u}}^{50}=$ $1.13, \phi_{d}^{50}=1.00, \bar{t}_{d}^{50}-\bar{t}_{u}^{50}=4.77$ hours, $E_{u}^{50}=1.00$, and $E_{d}^{50}=1.01$. This $\mathrm{K}^{50}$ is about 15 percent lower than $\mathrm{K}^{10}$ and $\mathrm{K}^{30}$ listed in tables 5 and 6.

Figure 10 presents $K^{10}$ and $K^{30}$ values against the time, which was chosen to be the middle of the travel time, $\bar{t}_{d}^{r}-t_{u}^{r}$, shown at the bottom 


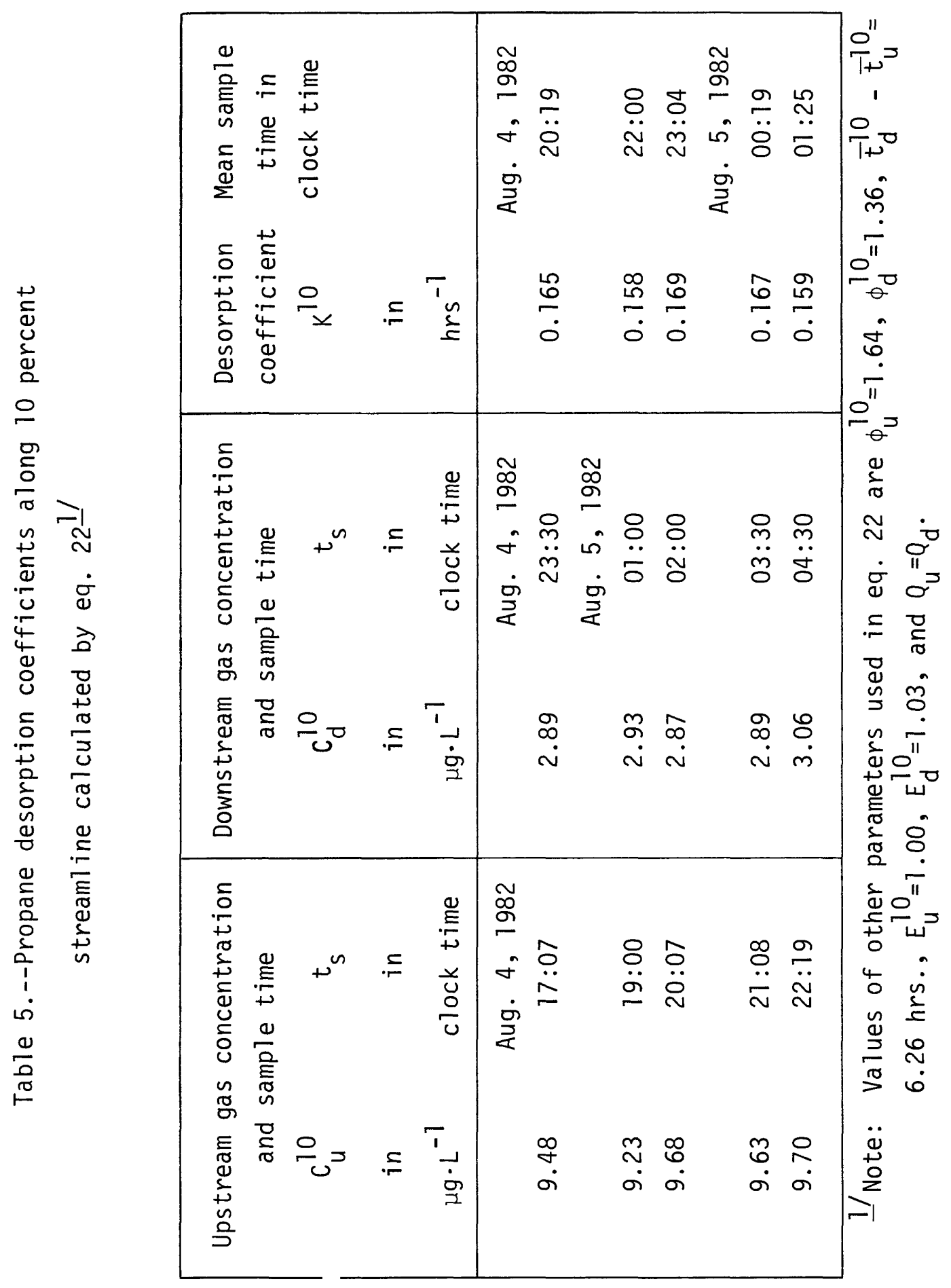




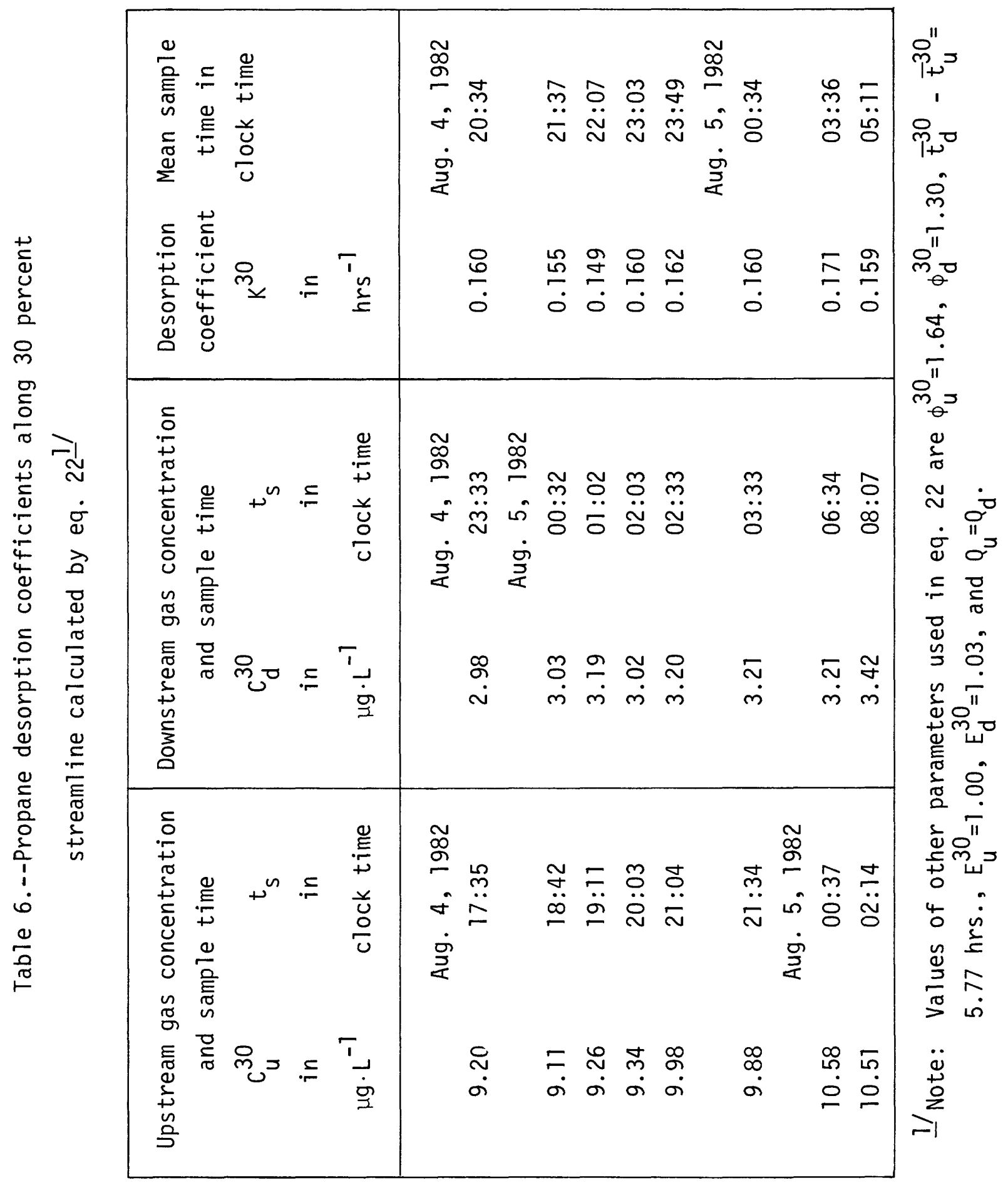




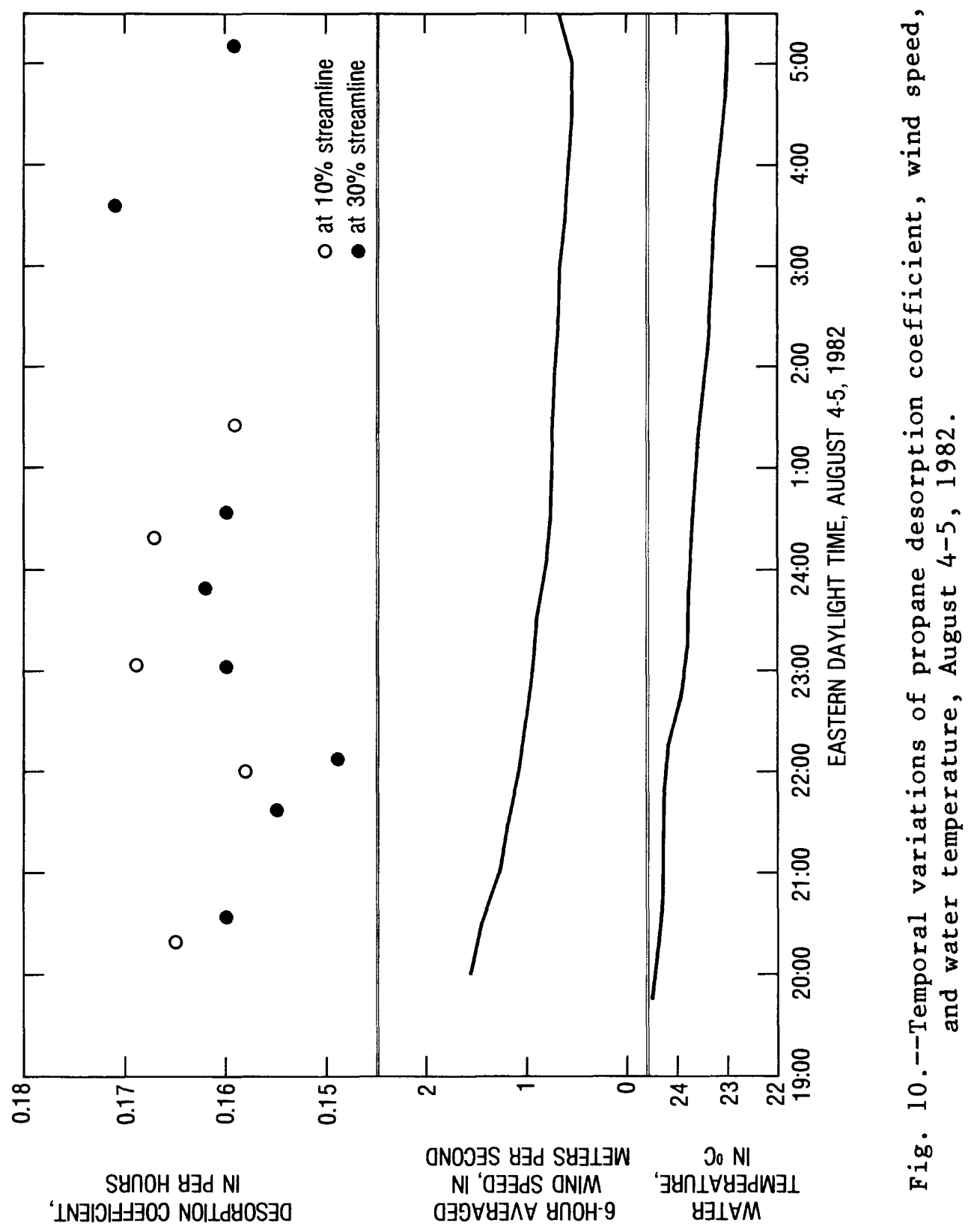


of tables 5 and 6 . The wind speed, $\bar{U}_{a}$, averaged for $\Delta t=6$ hours, is plotted against the middle time of averaging. It is very difficult to detect any consistent trend between high and low $k$ values and high and low values of $\overline{\mathrm{U}}_{\mathrm{a}}$. One reason for this appears to be that $\overline{\mathrm{U}}_{\mathrm{a}}$ values were generally lower than $1.5 \mathrm{~m} \mathrm{sec}^{-1}$ for the period. It is suspected that gas concentrations are not very sensitive to this magnitude of wind speeds when the wind speed is averaged over 6 hours. It appears that $\mathrm{k}^{10}=$ $0.164 \mathrm{hr}^{-1}$ and $\mathrm{k}^{30}=0.160 \mathrm{hr}^{-1}$, as averaged from tables 5 and 6 , probably represent the gas desorption coefficient generated by the channel flow turbulence with minor wind effects superimposed.

The above result is contrary to the previous findings reported by Jirka and Brutsaert (1984) and Holley and Yotsukura (1984). The earlier analyses used running time averages of gas concentration with or without the averaging over the streamlines in an effort to eliminate an uncertainty in $\phi$ values and also used $c_{u}^{50}$ data extensively. In the present. analysis, $c_{u}^{50}$ data were not considered as reliable as $c_{u}^{10}$ and $c_{u}^{30}$, and the criterion for steady-state mixing was applied rather strictly to select data. Because of some deficiencies in gas and dye data, the differences in the interpretation of data could not be resolved easily and will be left for future studies.

The first report explained the method of error estimation based on the standard analysis for the error propagation from measurements to to calculations (Ang and Tang, 1975; Holley, 1977). A similar estimation equation can be derived from eq. 22 by assuming that the travel time, $\bar{t}_{d}^{r}-\bar{t}_{u}^{r}$, and the correction term, $E(x, q)$, are determined without error. The approximate error equation is given by 


$$
\frac{\sigma\left(K^{r}\right)}{K^{T}}=\frac{1}{K^{T}\left(\bar{t}_{d}^{r}-\bar{t}_{u}^{r}\right)} \sqrt{\frac{2 \sigma^{2}(C)}{n_{c}(\bar{c})^{2}}+\frac{2 \sigma^{2}(Q)}{n_{Q}(\bar{Q})^{2}}+\frac{2 \sigma^{2}(\phi)}{n_{\phi}(\bar{\phi})^{2}}}
$$

where $\sigma^{2}$ denotes the population variance of the quantity indicated and $n_{\lambda}$ is the number of measurements of a variable $\lambda$ used to calculate the sample mean $\bar{\lambda}$. The square root term on the right side of eq. 40 designates the composite relative error of measuring $C, Q$, and $\phi$. As for $K^{10}$ and $R^{30}$ calculations, one may assume that the relative measurement errors, $\sigma(C) / \bar{C}$ and $\sigma(Q) / \bar{Q}$, are 3 and 5 percent, respectively, with $n_{c}=n_{Q}=1$. As for $\sigma(\phi) / \bar{\phi}$, the error at the upstream section was assumed to be 5 percent, but the downstream error was increased to 10 percent because $\phi_{d}^{50}$ was assumed to be 1.00 based on the result of simulation. Thus, the average $\sigma(\phi) / \bar{\phi}$ was 8 percent with $n_{\phi}=1$. The composite measurement error thus becomes 14 percent. Assuming $\mathrm{K}^{10}$ and $\mathrm{K}^{30}$ as $0.16 \mathrm{hr}^{-1}$, the estimted relative error of $\mathrm{K}^{10}$ and $\mathrm{K}^{30}$ is 14 and 15 percent, respectively. As for $k^{50}$, the variation of $\mathrm{C}_{\mathrm{u}}^{50}$ can not be considered as random relative to the steady-state, so that eq. 40 is not applicable.

\section{Wind Function, $\psi$}

The methodology used in the previous section for computing desorption coefficients over the reach between the two measurements sections failed to demonstrate any clear effects of wind. In this section, an alternative method is used to estimate the effects of wind on desorption; such effects appear to be very obvious at the upstream section, notably the concentration history at the 30 percent streamline. Some of the concentration data, which were not usable in the $K^{\Gamma}$ calculation in the previous section, may now be utilized for evaluation of the wind effect on desorp- 
tion coeffictents by use of eq. 25. By the definition given previously, all gas data shown in figures 8 and 9 are considered to be approximately at steady state with respect to the averaged wind speed, $\vec{U}_{a}\left(t_{s}\right)$, as illustrated at the bottom of the figures.

At the 30 percent streamline of the upstream section, the period between 3:00 and 8:00 pm, Aug. 4, was chosen as a high wind period, because $\mathrm{C}_{\mathrm{u}}^{30}$ was practically constant despite the fact that $\bar{U}_{a}\left(t_{s}\right)$ with $\Delta t=3$ hours varied between 2.0 and $2.9 \mathrm{~m} \mathrm{sec}^{-1}$. As for the period that did not show the effect of wind, the one between 3:00 and 5:00 am, Aug. 5, appeared to be a good choice, because $c_{u}^{30}$ remained constant while $\bar{U}_{a}\left(t_{s}\right)$ was about $0.6 \mathrm{~m} \mathrm{sec}^{-1}$. The data after 5:00 am were excluded from consideration because of the reason cited previously. The centers of these two periods were chosen as $t_{H}$ and $t_{L}$ to calculate the wind function, $\psi$, by use of eq. 25. This calculation is shown in the top row of table 7. Another high wind period for $\mathrm{C}_{\mathrm{u}}^{30}$ was chosen between 9:00 pm and 10:00 pm, Aug. 4, when $\bar{U}_{a}$ was about $1.5 \mathrm{~m} \mathrm{sec}^{-1}$ and $C_{u}^{30}$ was constant at approximately $10 \mu g \mathrm{~L}^{-1}$. Utilizing the same $t_{L}$ period as the first calculation, the second calculation of $\psi$ is shown in the middle row of table 7 . Note that these gas concentrations were observed at the 30 percent streamline, which is the streamline of the tracer source. Thus, the above wind funtions may be considered to be $\psi^{30}$.

The gas concentrations on the 10 percent streamline show a trend similar to those on the 30 percent streamline. Eq. 25 may be applied to $\mathrm{C}_{\mathrm{u}}^{10}$ values using the same $t_{H}$ and $t_{L}$ periods used in the first calculation. The third calculation is shown at the bottom row of table 7 . Note that the value of $\psi$ is smaller than the first and also that this $\psi$ represents the wind 


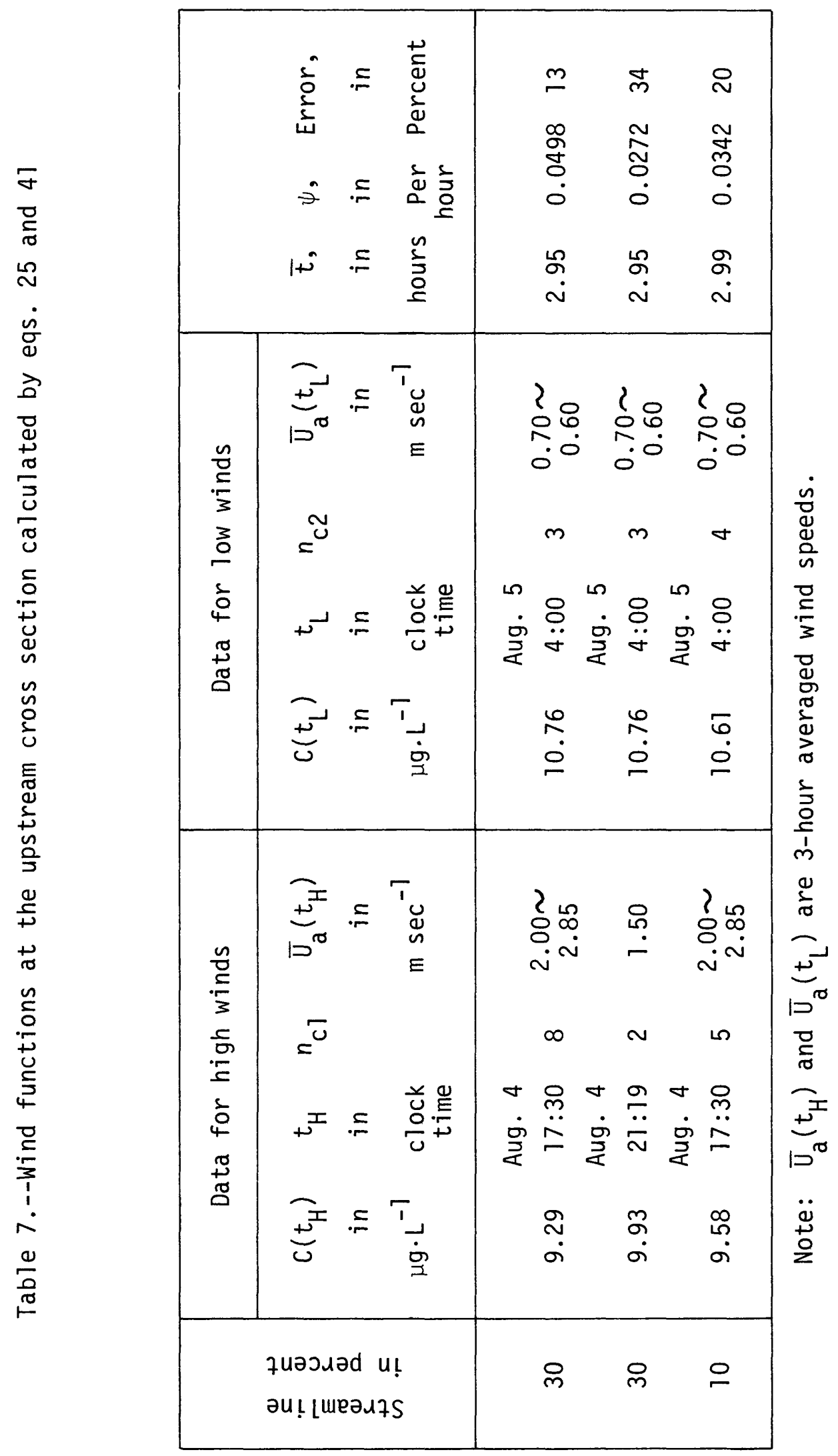


effect as the gas tracer traversed from the source streamline of 30

percent to the measurement streamline of 10 percent.

The error estimate of $\psi$ calculations may be obtained by again applying the method of Tang and Ang (1975) to eq. 25. It is given by,

$$
\frac{\sigma(\psi)}{\psi}=\frac{1}{\psi \bar{t}} \sqrt{\frac{\sigma^{2}\left[\mathrm{C}\left(\mathrm{t}_{H}\right)\right]}{n_{c 1}\left[\overline{\mathrm{C}\left(\mathrm{t}_{H}\right)}\right]^{2}}+\frac{\sigma^{2}\left[\mathrm{C}\left(\mathrm{t}_{L}\right)\right]}{n_{c 2}\left[\overline{\left.\mathrm{C}\left(\mathrm{t}_{L}\right)\right]^{2}}\right.}}
$$

Assuming that the relative error of gas concentration measurement is 3 percent, the relative estimated error of the three calculations are shown also in table 7 . In addition to these formal error calculations, one needs to recall that the gas injection rate between 1:00 and 7:00 pm, Aug. 4, may have been lower than at other periods because the line pressure readings of the second and third tanks were lower as mentioned previously. This could have resulted in lower values of $C_{u}^{30}$ and $C_{u}^{10}$ between 4:00 and 10:00 pm, Aug. 4, and thus, in higher calculated $\psi$ values.

There was no reason not to apply eq. 25 to the gas concentrations observed at the downstream cross section, even though the variations of gas concentration with wind averaged over 9 hours were much smaller than those at the upstream cross section. The calculation of $\psi$ using $c_{d}^{30}$ showed that it is on the order of $0.015 \mathrm{hr}^{-1}$ for $\bar{U}_{a}$ at the level of $2 \mathrm{~m}$ $\mathrm{sec}^{-1}$. The relative error of calculation by use of eq. 41 is about 23 percent. This calculated $\psi$ is much lower than $\psi^{\prime}$ 's observed at the upstream cross section and indicates that the wind shear becomes less effective in increasing the gas desorption as the averaging period, $\Delta t=\bar{t}$, increases. The $c_{d}^{10}$ and $c_{d}^{50}$ data were considered unsuitable for calculation because of the loss of data after 8:00 am, Aug. 5, as explained previously. 


\section{DISCUSSION}

The following discussion of the results of the field test is divided into sections on field procedures and on gas tracer desorption. In the section on field procedures, the first half of the discussion deals with the improvements needed for the two-dimensional method. The second half discusses new recommendations on gas tracers in general, which should be considered as an addition to those discussed earlier in the first report. The calculated desorption coefficients and wind functions, though limited in number, appear to be within acceptable ranges of error. They provide new quantitative information on the gas desorption along streamlines under the influence of winds. These will be discussed in two separate sections following the field-procedures section.

\section{Field Procedures}

The most important lesson of the field test is that the two-dimensional tracer method requires a more intense preparation and more precise execution than the one-dimensional measurement. First of all, the preliminary dye test should be conducted much more thoroughly than that of Aug. 3, 1982, in order to obtain a concrete idea of transverse tracer-plume configuration--in particular, at the upstream cross section--because an accurate prediction of the transverse mixing coefficient for a particular test reach is currently impossible. This is evident from the comparison of $\phi$ values used in the test planning with measured values at the upstream cross section. 
The erratic behavior of $c_{u}^{50}$ may be the result of possible transverse movement of tracer plumes and streamlines due to high winds. It appears that the location of upstream cross section was too close to the injection site in the present test. In the future, this difficulty could be avoided by a good preliminary dye test and the proper choice of sampling sections and/or locations, where the transverse gradient of dye concentration is small and stable. According to figure 7 , the magnitude of $\Delta \phi / \Delta \eta$ should be smaller than 3.25 at any measurement location. Needless to say, tracer concentration measurements should not be made at the edge of plume, where tracer concentration may be too low for accurate analysis.

Even though the method described here is based on an instananeous injection of dye tracer, a good alternative method under high wind conditions may be continuous dye injection, which permits repeated measurement of the steadystate dye concentration. In this manner, the time varying mass distribution factor and gas concentration could be measured somultaneously. Unfortunately, however, the present test could not evaluate such merits because of the failure in dye injection scheme. The relative merits of instantaneous versus continuous dye injection require future evaluations.

For two-dimensional tests, the importance of an accurate determination of streamline locations can not be overemphasized. Therefore, it is highly desirable to have repeated discharge measurements at sampling cross sections. This is also desirable from the viewpoint of reducing the measurement error according to eq. 40. From the present experience, however, the choice of a source streamline at 30 percent appears to be satisfactory. 
With regard to the problem of gas sampling, the present test provided some useful information. This information, which is in addition to the information discussed in the first report, is applicable to the one-dimensional test as well. It was shown that, if one places the wrong side of the septum in contact with sample water, the subsequent adsorption of gas onto the septum renders the sample almost useless. This unexpected mishap has also been experienced by the Wisconsin District and appears to warrant a clear warning to the sampling crew before the field work.

All gas samples in the present test were packed at the test site and shipped directly to the U.S. Geological Survey Central Laboratory. This apparently created an uncertainty in tracing the cause of air bubble formation, which was detected in a large number of gas samples, at the time of gas chromatographic analysis. A better practice would be to bring all gas samples back to the office, retighten the vial caps, check for air bubbles in the samples, and select the appropriate gas samples in reference to field notes for final shipping to the Central Laboratory. This may delay the shipping of samples but will improve the reliability of gas samples and reduce the cost of gas analysis by not having unnecessary samples analyzed. The collection and analysis of dissolved gas samples requires far more subtle and expensive work than those of dye, so that the importance of careful handling of gas samples can not be overemphasized.

Even though three $45-\mathrm{kg}$ propane tanks appeared to have performed nominally during the 21-hr injection period, it will be very desirable in a future test to have a means of checking the gas inflow rate from time to time, such as by weighing. If no method is feasible in the field, at least a careful laboratory test of the pressure gage and flow regulator should be performed prior to their 
use in the field. The necessity for this information was discussed previously concerning the wind function calculation and also in reference to the erratic behavior of gas concentration around 6:00 am, Aug. 5, as illustrated in figure 8.

\section{Desorption Coefficient, $\mathrm{K}^{\mathrm{T}}$}

In examining the total gas desorption coefficients calculated from eq. 22 , the $\mathrm{K}^{50}$ value does not appear to merit further consideration because of the problem with $\mathrm{C}_{\mathrm{u}}^{50}$ and $\phi_{\mathrm{u}}^{50}$ data as discussed previously. Furthermore, in view of the lack of correlation of $k^{10}$ and $k^{30}$ with the 6-hr-averaged wind speed, as shown in figure 10, one may assume that these desorption coefficients were mainly generated by channel turbulence. The average $k^{10}$ from table 5 is $0.164 \mathrm{hr}^{-1}$ and $\mathrm{K}^{30}$ from table 6 is $0.160 \mathrm{hr}^{-1}$ at the average water temperature of $23.7^{\circ} \mathrm{C}$. When converted to the values at $20^{\circ} \mathrm{C}$ by use of the formula of Elmore and West, $(1961), \mathrm{K}^{10}(20)=0.150 \mathrm{hr}^{-1}$ and $\mathrm{K}^{30}(20)=0.147 \mathrm{hr}^{-1}$.

In the two-dimensional study, the conversion of desorption coefficient to the film coefficient of mass transfer (Holley, 1973), $K_{L}^{r}=H^{r} K^{r}$, requires that the reach-averaged depth, $H^{r}$, be defined for the stream tube that $\mathrm{K}^{\mathrm{r}}$ represents. Strictly speaking, such depth must be calculated from the streamtube discharge, the reach length, the mean travel time, and the reach-averaged stream-tube width. Because such reach-averaged width can be obtained only from the measured relation, $q$ versus $z$, at a large number of cross sections in the reach, the calculation of $\mathrm{H}^{\Gamma}$ is not feasible in most field tests. Thus, despite a successful measurement of $\mathrm{K}^{\mathrm{T}}$ along two streamlines, the only con- 
clusion from the present test is that the propane desorption coefficient at $20^{\circ} \mathrm{C}$ is $0.15 \mathrm{hr}^{-1}$, probably for the major part of the left half channel of the Chenango River reach tested.

It is of some interest to calculate the film coefficient, $k_{L}$, from the reach-averaged cross-sectional depth, $\mathrm{H}$, of the Chenango River and compare the $K_{L}$ value with values obtained by the steady-state method for the Cowaselon Creek under two different discharges as described in the first report. In reference to the existing literature on this subject, the primary relation of $\mathrm{K}_{\mathrm{L}}$ appears to be with the product of velocity and slope, US, which represents the average rate of potential energy loss in open channels for a unit weight of water (Dobbins, 1965; Parkhurst and Pomeroy, 1972; and Rathbun, 1982). Figure 11 presents the three film coefficients measured by the steady-state method with pertinent information tabulated. All flow parameters are final reachaveraged measured values and supersede previous values quoted in this report and the first report.

It is seen that the three points are approximately on a straight line, whose slope is about 0.5 . This functional relation appears to agree the best with the equation of Parkhurst and Pomeroy (1972), for which the slope is 0.375, however. Note that figure 11 is presented as a summary of the results from the two assessment studies and is not intended for a generalized correlation, for which three data points are obviously not adequate. 


\begin{tabular}{|c|c|c|c|}
\hline 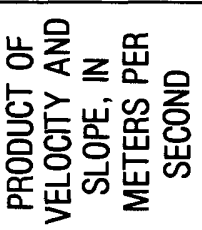 & 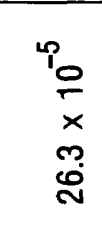 & $\begin{array}{l}\text { To } \\
x \\
\frac{1}{x}\end{array}$ & 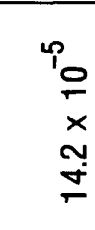 \\
\hline 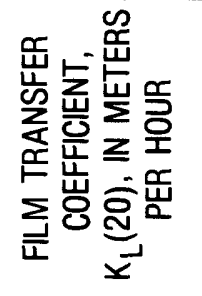 & 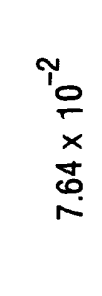 & 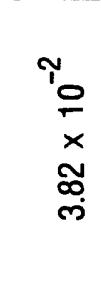 & $\begin{array}{l}\text { To } \\
\text { To } \\
x \\
\frac{m}{i n}\end{array}$ \\
\hline 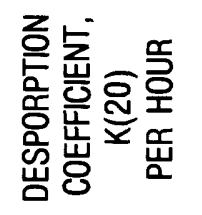 & $\frac{\sigma}{\dot{\sigma}}$ & $\frac{\mathscr{O}}{\circ}$ & $\frac{\Xi}{\sigma}$ \\
\hline 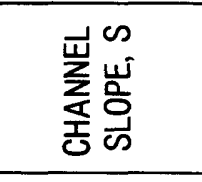 & 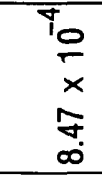 & $\begin{array}{l}\text { To } \\
x \\
x \\
p \\
\dot{y}\end{array}$ & 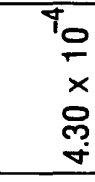 \\
\hline 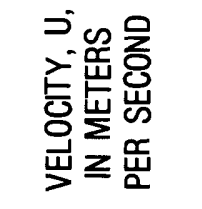 & స్ & 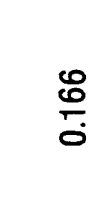 & প্ల్ల \\
\hline 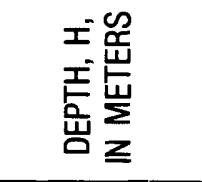 & గ్రి & ஜூల & $\stackrel{\text { ? }}{\circ}$ \\
\hline 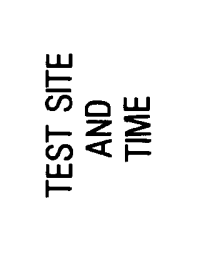 & 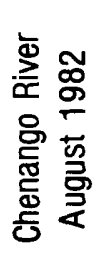 & 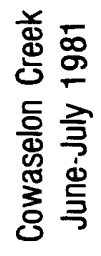 & 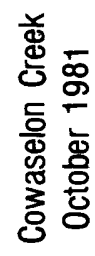 \\
\hline
\end{tabular}

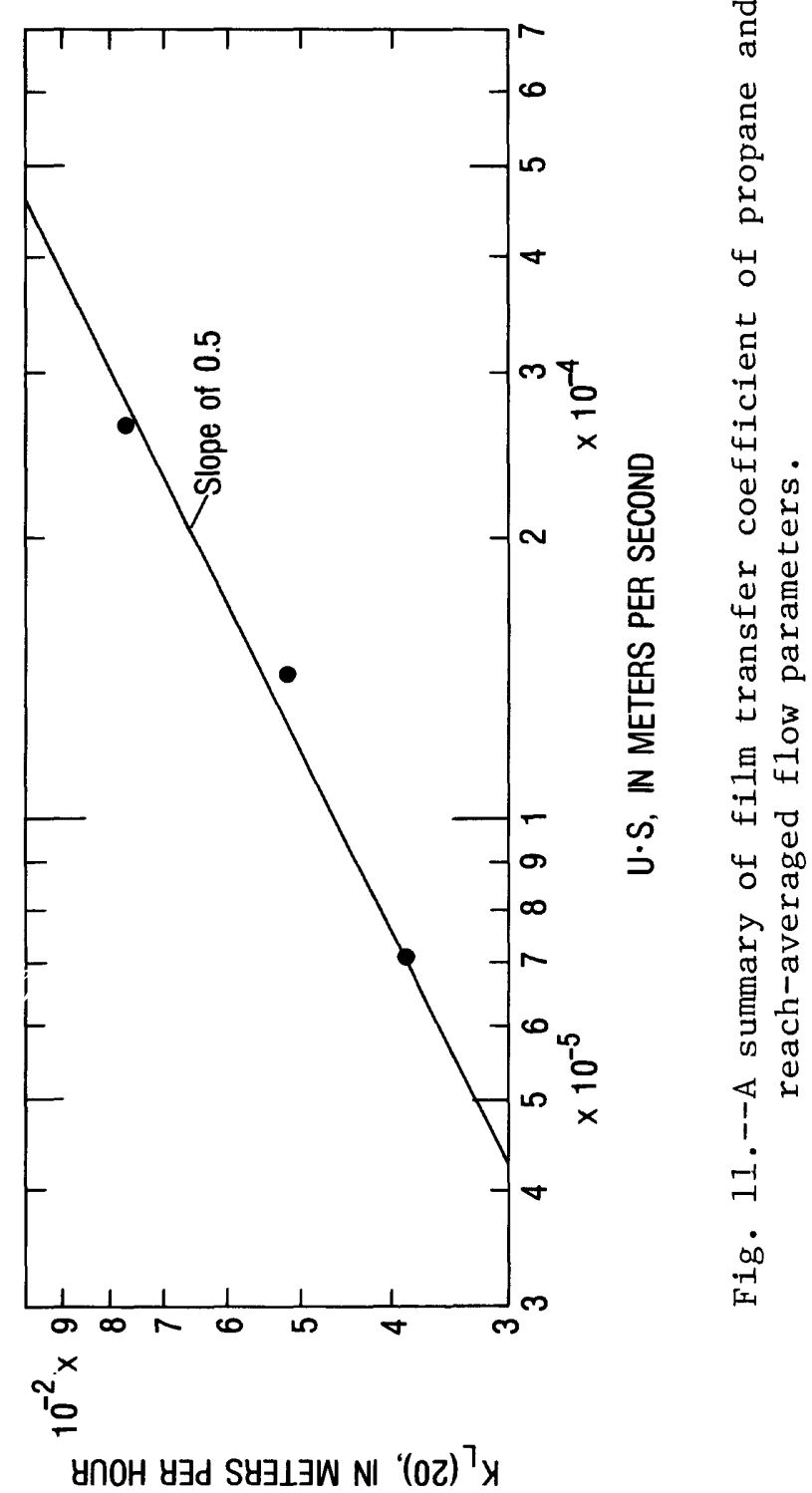




\section{Wind Function, $\psi$}

Figure 12 illustrates the relation of the wind function, $\psi$, with the 3-hraveraged wind speed, $\overline{\mathrm{u}}_{\mathrm{a}}$. Note that $\psi$ values were calculated by eq. 25 for the reach between the source and the upstream cross section, whereas $\bar{U}_{a}$ was observed $3.7 \mathrm{~km}$ downstream from the upstream section. The right ordinate of figure 12 was prepared by assuming first that $K=0.16 \mathrm{hr}^{-1}$, which was obtained in the previous section by use of eq. 22 , is not influenced by wind so that it represents the desorption coefficient generated by channel turbulence, $K_{c}$. Secondly, it is assumed that the above $k_{c}$ value obtained for the reach between the upstream and downstream sections is applicable to this reach. Considering all these assumptions and the accuracy of $\psi$ calculations shown in table 7 , one must conclude that figure 12 represents a first-order approximation of the wind effect at the Chenango River site. It is also important to remember that eq. 25 assumes that the gas flow rate, $m$, and the mass distribution factor, $\phi$, are independent of time. The present test was not completely successful in resolving these problems.

Nevertheless, it is significant that the wind function was found to be as much as 30 percent of $K_{c}$ when the $3-h r$ averaged wind speed is approximately $2.5 \mathrm{~m} \mathrm{sec}^{-1}$. The general trend shown in figure 12 appears consistent with the measurements obtained from laboratory flumes and open oceans for purely wind controlled conditions (Jähne, 1980). Jirka and Brutsaert (1984) arrived at a similar conclusion on the wind effects at the Chenango site, even though the detailed interpretation of data was different from the present report. 


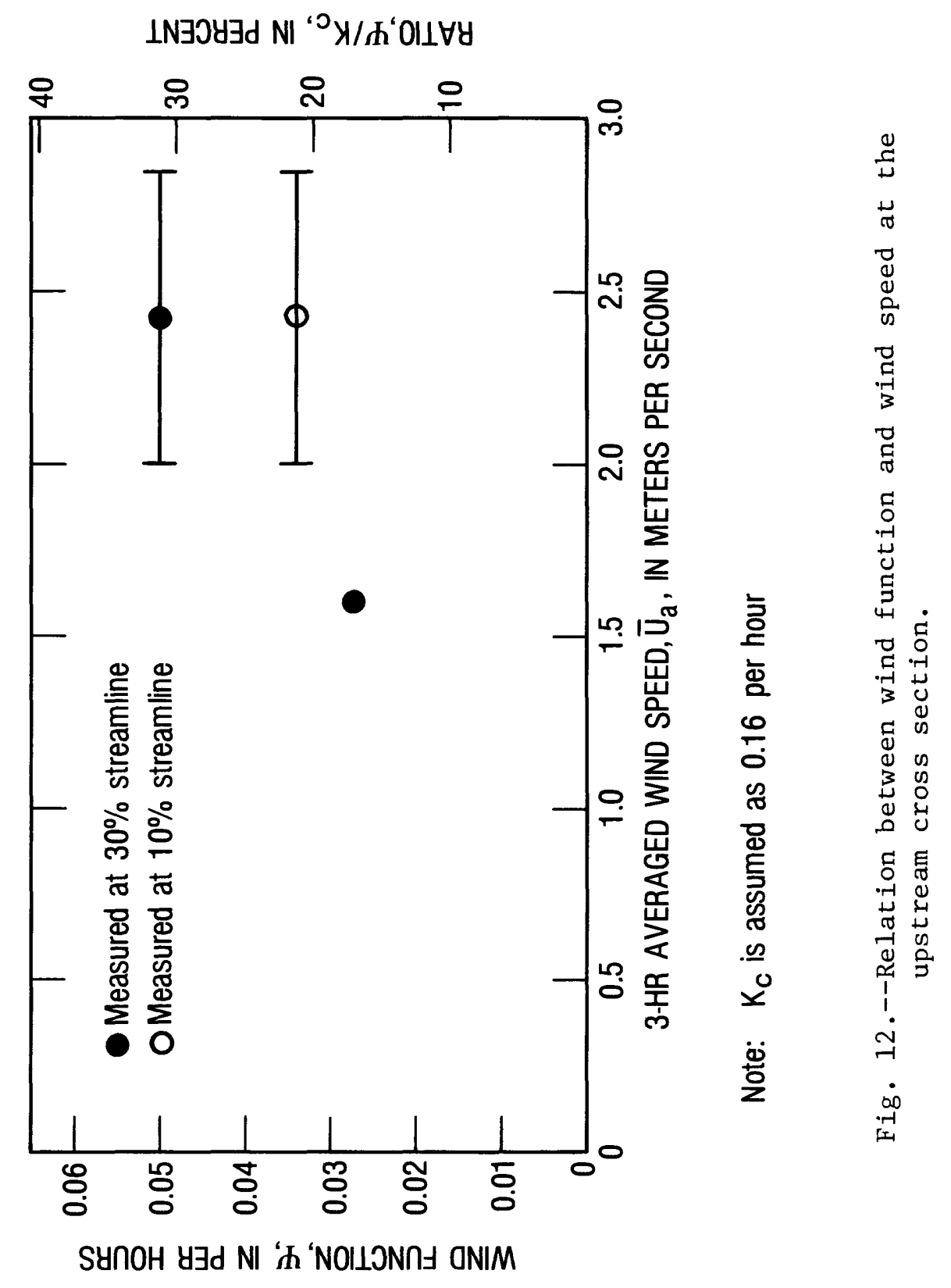


On the other hand, one notes that the wind effect on gas desorption appears to decrease as the wind averaging period increases to 6 to 9 hours. This trend is clearly shown in the temporal variation of gas concentration in figure 9. At this downstream cross section, the 9-hr-averaged wind speed varied from $0.6 \mathrm{~m} \mathrm{sec}^{-1}$ to $2.3 \mathrm{~m} \mathrm{sec}^{-1}$. The $\psi$ values for the downstream section were much smaller than those shown in figure 12 . Figure 10 also shows that $\mathrm{K}^{10}$ and $\mathrm{K}^{30}$ calculated from eq. 22 are not sensitive to the variation of the 6-hr-averaged wind speed between 0.6 and $1.5 \mathrm{~m} \mathrm{sec}^{-1}$.

It is worth repeating here that the wind function, $\psi$, is an empirical definition and is not the same as the wind-generated desorption coefficient, $\mathrm{K}_{a}$, even though $\psi$ is probably related closely to $\mathrm{K}_{a}$. Because no satisfactory analytical models for wind-generated gas desorption in open channels are available at the present time, the empirical approach such as the present one will be useful in supplying quantitative information about the effects of wind.

\section{SUMMARY}

The present assessment of the propane-gas tracer method indicates that the two-dimensional steady-state method is feasible for the measurement of gas desorption, including an evaluation of wind effect, in a relatively short reach of a wide river. The equation for the steady-state gas-tracer concentration was derived in such a manner that it is applicable not only to any two-dimensional streamline but also to a one-dimensionable plume in a nonuniform river. In the latter situation, the present equations supersede the equations presented in the first report. Additionally, a simple empirical method was devised for the one-station measurement of wind effect on gas desorption and is applicable to two- and one-dimensional tracer plumes. 
Despite the loss of a large number of gas samples because of inadequate test planning and several mishaps in sample handling, the calculated gas desorption coefficient of the Chenango River under low winds is consistent with two other values obtained previously for the Cowaselon Creek in the sense that three coefficients are well correlated with reach-averaged depth, velocity, and channel slope. The increase of the gas desorption coefficient due to high wind was substantial and is consistent with the measurements from laboratories and fields of gas desorption under purely wind-controlled conditions.

On the other hand, the present two-dimensional method does not appear to be as ready for immediate operational application as was the one-dimensional method after the Cowaselon Creek tests. For low wind conditions, all sampling should be done at locations where the transverse variation of tracer concentration is small and stable. This requires a thorough preliminary dye test and some familiarity with the behavior of tracer plumes. Repeated discharge measurements are desirable for accurate determination of streamlines. Under high wind conditions, the above requirements become even more severe. Under certain circumstances, the continuous dye injection will be needed to measure the time-dependent mass distribution factor. It may be desirable to combine the two-cross-section method to measure the channel-generated desorption coefficient with the one-cross-section method to measure effects of wind. However, because of conflicting requirements for reach length for the two methods, it may be difficult to combine these methods into a simple operational scheme. Finally, the importance of maintaining a constant gas injection rate and of careful handling of gas samples as discussed in this and the first report can not be overemphasized. 


\section{REFERENCES}

Ang, A. H-S., and Tang, W.H., 1975, Probability concepts in engineering planning and design: John Wiley and Sons, Inc., New York, 409 p.

Dobbins, W.E., 1964, Mechanism of gas absorption by turbulent liquid: Proceedings, International Conference on Water Pollution Research, Sept. 1962, Pergamon Press, Inc., London, p. 61-76.

Elmore, H.L., and West, W.F., 1961, Effect of water temperature on stream reaeration: Am. Soc. Civil Engineers, Jour. of Sanitary Eng. Div., v. 87, no. SA6, p. 59-71.

Fischer, H.B., 1973, Logitudinal dispersion and turbulent mixing in open-channel flow: Annual Review of Fluid Mechanics, volume 5, Annual Review Inc., Palo Alto, Calif., p. 59-78.

Fisher, H.B., List, E.J., Koh, R.C.Y., Imberger, J. and Brooks, N.H., 1979, Mixing in inland and coastal waters: Academic Press., New York, 483 p.

Holley, E.R., 1973, Diffusion and boundary layer concepts in aeration through liquid surfaces: Water Research, volume 7, Pergamon Press, London, p. 559-573.

Holley, E.R., 1977, Dilution method of discharge measurement in pipes: Proceedings of the symposium on flow in open channels and closed conduits, National Bureau of Standards, Special Publication 484, p. 395-421.

Holley, E.R., and Yotsukura, N., 1984, Field techniques for reaeration measurements in rivers: Gas Transfer at Water Surfaces edited by W. Brutsaert and G.H. Jirka, D. Reidel Publishing Co., Dordrecht, Netherland, p. 381-401

Hubbard, E.F., Kilpatrick, F.A., Martens, L.A., and Wilson, J.F. Jr., 1982, Measurement of time of travel and dispersion in streams by dye tracing: Techniques of Water-Resources Investigations, U.S. Geological Survey, Chap. A9, Book 3, 44 p.

Jähne, B., 1980, Zur Parametrisierung des Gasaustausches mit Hilfe von Laborexperimenten: Doktor Thesis, Univ. Heidelberg.

Jirka, G.H., and Brutsaert, W., 1984, Measurements of wind effects on water-side controlled gas exchange in riverine systems: Gas Transfer at Water Surfaces edited by W. Brutsaert and G.H. Jirka, D. Reidel Publishing Co., Dordrecht, Netherland, p. 437-446.

Parkhurst, J.D., and Pomeroy, R.D., 1972, 0xygen absorption in streams: Am. Soc. Civil Engineers, Jour. of Sanitary Eng. Div., v. 98, no. SA1, p. 101-124. 
Plate, E.J., and Friedrich, R., 1984, Reaeration of open channel flow: Gas Transfer at Water Surfaces edited by W. Brutsaert and G.H. Jirka, D. Reidel Publishing Co., Dordrecht, Netherland, p. 333-346.

Rainwater, K.A., and Holley, E.R., 1984, Laboratory studies on hydrocarbon tracer gases: Am. Soc. Civil Engineers, Jour. of Environmental Engineering, v. 110, no. 1, p. 27-41.

Rathbun, R.E., 1979, Estimating the gas and dye quantities for modified tracer technique measurement of stream reaeration coefficients: U.S. Geological Survey Water-Resources Investigations 79-27, 42 p.

Rathbun, R.E., 1982, Volatilization of organic compounds from streams: Am. Soc. Civil Engineers, Jour. of Environmental Eng. Div., v. 108, no. EE5, p. 973-989.

Taylor, G.I., 1959, The present position in the theory of turbulent diffusion: Advances in Geophysics, volume 6, Academic Press, New York p. 101-112.

Tsivoglou, E.C., O'Connell, R.L., Walter, C.M., Godsil, P.J., and Logsdon, G.S., 1965, Tracer measurement of atmospheric reaeration - I. Laboratory studies: Jour. of Water Pollution Control Fed., v. 37, no. 10, p. 1343-1362.

Wylie, C.R., Jr., 1951, Advanced engineering mathematics: McGraw-Hill Book Co., Inc., New York, $640 \mathrm{p}$.

Yotsukura, N., and Cobb, E.D., 1972, Transverse diffusion of solute in natural streams: U.S. Geol. Survey Prof. Paper 582-C, 19 p.

Yotsukura, N., and Kilpatrick, F.A., 1973, Tracer simulation of soluble waste concentration: Am. Soc. Civil Engineers, Jour. Environmental Eng. Div. v. 99, no. EE4, p. 499-515.

Yotsukura, N., and Sayre, W.W., 1976, Transverse mixing in natural channels: Am. Geophys. Union, Water Resources Research, v. 12, no. 4, p. 695-704.

Yotsukura, N., Stedfast, D.A., Draper, R.E., and Brutsaert, W.H., 1983, An assessment of steady-state propane-gas tracer method for reaeration coefficients - Cowaselon Creek, New York: U.S. Geol. Survey Water-Resources Investigations $83-4183,88 \mathrm{p}$. 